Portland State University

PDXScholar

Mechanical and Materials Engineering Faculty

Publications and Presentations

Mechanical and Materials Engineering

$12-5-2018$

\title{
Quenchant Cooling Curves, Rewetting, and Surface Heat Flux Properties of Vegetable Oils
}

\author{
Rosa L. Simencio Otero \\ Universidade de São Paulo \\ Jônatas M. Viscaino \\ Universidade de São Paulo \\ Jun Xu \\ Shanghai Jiaotong University \\ Jianfeng $\mathrm{Wu}$ \\ Shanghai Jiaotong University \\ George Totten \\ Portland State University, getotten@gmail.com
}

See next page for additional authors

Follow this and additional works at: https://pdxscholar.library.pdx.edu/mengin_fac

Part of the Mechanical Engineering Commons

Let us know how access to this document benefits you.

\section{Citation Details}

Simencio Otero, R. L., Viscaino, J. M., Xu, J., Gu, J., Totten, G. E., and Canale, L. C. F., “Quenchant Cooling Curves, Rewetting, and Surface Heat Flux Properties of Vegetable Oils," Materials Performance and Characterization.

This Article is brought to you for free and open access. It has been accepted for inclusion in Mechanical and Materials Engineering Faculty Publications and Presentations by an authorized administrator of PDXScholar. Please contact us if we can make this document more accessible: pdxscholar@pdx.edu. 


\section{Authors}

Rosa L. Simencio Otero, Jônatas M. Viscaino, Jun Xu, Jianfeng Wu, George Totten, and Lauralice C.F. Canale 
Manuscript received March 5, 2018; accepted for publication May 9, 2018; published online December 5, 2018.

1 Department of Materials Engineering, São Carlos School of Engineering, University of São Paulo, Av. João Dagnone, 110, São Carlos SP 13563-120, Brazil (Corresponding author), e-mail: rosa.simencio@gmail.com, (D) https://orcid.org/00000002-1974-6406

2 Department of Materials Engineering, São Carlos School of Engineering, University of São Paulo, Av. João Dagnone, 110, São Carlos SP 13563-120, Brazil, (D) https://orcid.org/0000-00020193-1902 (L.C.F.C.), (iD http:// orcid.org/0000-0001-8865-3396 (J.M.V.)

3 Institute of Materials Modification and Modelling School of Materials Science and Engineering, Shanghai Jiaotong University, Dongchuan Rd., Shanghai 200240, China, (D) http://orcid. org/0000-0003-4280-3429 (J.X.), (i) https://orcid.org/00000002-0762-6976 (J.G.)

${ }^{4}$ Department of Mechanical and Materials Engineering, Portland State University, Portland, OR, USA, (D) https://orcid.org/00000002-7313-1437
Rosa L. Simencio Otero, ${ }^{1}$ Jônatas M. Viscaino, ${ }^{2}$ Jun $\mathrm{Xu},{ }^{3}$ Jianfeng $\mathrm{Gu},{ }^{3}$ George E. Totten, ${ }^{4}$ and Lauralice C. F. Canale ${ }^{2}$

\section{Quenchant Cooling Curves, Rewetting, and Surface Heat Flux Properties of Vegetable Oils}

\section{Reference}

Simencio Otero, R. L., Viscaino, J. M., Xu, J., Gu, J., Totten, G. E., and Canale, L. C. F., "Quenchant Cooling Curves, Rewetting, and Surface Heat Flux Properties of Vegetable Oils," Materials Performance and Characterization https://doi.org/10.1520/

MPC20180042. ISSN 2379-1365

\section{ABSTRACT}

Vegetable oils are currently used for biodegradable and renewable base stocks for quenchant formulation. However, there are relatively few references relating to their true equivalency, or lack thereof, comparative to the quenching performance of petroleum oil-based quenchant formulations. To obtain an overview of the variability vegetable oil quenching performance, the cooling curves and rewetting properties were determined, and the surface heat flux properties were calculated. The vegetable oils that were studied included canola, coconut, corn, cottonseed, palm, peanut, soybean, and sunflower oils. Cooling curves were obtained using the Tensi multiple-surface thermocouple $15 \mathrm{~mm}$ diameter by $45 \mathrm{~mm}$ cylindrical Inconel 600 probe (Note: The multiple thermocouple probe was custom manufactured to conform to a drawing provided by: Heattec located at Seglaregatan 1C, 30290 Halmstad, Sweden). For comparison, similar data was obtained with Houghto-Quench H100, a conventional (slow) petroleum quenchant oil, and Houghto-Quench HKM, an accelerated (fast) petroleum oil quenchant (Houghton International Inc., Valley Forge, PA). The results of this work will be discussed here.

\section{Keywords}

quenchant, vegetable oil, cooling curve, rewetting, heat flux 


\section{Introduction}

An earlier review summarized the use of vegetable and animal oils as quenchants from 1850 until the early 2000s [1]. The use of animal and vegetable oils in industrial oil applications fell out of favor after World War II. However, there has been a revival in the interest in these oils as biodegradable, renewable base stocks for industrial oil formulation. There has been a relative explosion in the number of more recent references reporting the use of these natural oils as quenchants for the following reasons [2]:

(1) Most of the vaporizable, liquid quenchants used in the heat-treating industry are based on petroleum oil base stocks, which have been shown to be toxic to the environment and are often difficult to dispose of after use. Vegetable oil-based quenchants are typically much more biodegradable and less persistent when released to the soil and groundwater $[3,4]$. In addition, the potential for petroleum-based oil spills to lead to environmental damage leads to undesirable media attention [5]. Therefore, they are an attractive option when government regulations inhibit or prevent the use of petroleum oil quenchants [6].

(2) Kinawy, El-Hamidi, and Abdallah have reported that petroleum oils are carcinogenic and furthermore that medical records have shown that they may cause eczema and oil acne. Prolonged exposure to petroleum oil mist may cause irritation of the respiratory tract [5].

(3) To be commercially competitive, companies have developed bio-based, environmentally friendly products without the problems posed by the use of petroleum oil-based fluids [7]. In the United States, in the 2002 Farm Bill (Farm Security and Rural Investment Act, published January 11, Federal Register), Section 9002 includes language directing all Federal Government Agencies to give preference to "bio-based" products [6].

(4) Vegetable oils are renewable and therefore provide the possibility of contributing to the goal of energy independence and security [6].

One of the earliest, more rigorous studies of vegetable, animal, and fish oils as alternatives to petroleum oil for quenching steel was reported by Tagaya and Tamura [8,9]. Although these fluids were shown to exhibit poorer oxidative stability relative to petroleum oil quenchants, they were shown to provide more uniform heat transfer because of their minimal film boiling and nucleate boiling behavior, which is important if distortion and cracking are to be minimized. In addition, these renewable oils were shown to be effective for quenching a broad range of carbon and alloy steels.

In more recent work, de Souza et al. [10,11], Prabhu and co-workers [12,13], and Agboola et al. [14] extensively characterized a wide variety of seed oils, such as corn oil, canola oil, sunflower oil, soybean oil, and others, by cooling curve analysis using small (typically $\leq 12.5 \mathrm{~mm}$ ) cylindrical probes usually constructed from Inconel 600 or a stainless steel. In addition to the characterization of cooling time and cooling rates of these oils, their heat transfer properties were determined using either a simplified computational methodology $[15,16]$ or finite element analysis [11-13].

Heat transfer characterization of palm oil and canola oil relative to a commercially formulated petroleum oil was also reported using a proprietary Liscic/Petrofer $50-\mathrm{mm}$ diameter Inconel probe (Petrofer $\mathrm{GmbH}$, Hildesheim, Germany) to simulate workshop quenching conditions $[17,18]$.

In addition to heat transfer properties, it is also of vital importance to assess the rewetting properties of a quenchant. The rewetting ability of a quenchant is a measure of the 
overall surface uniformity of the cooling process. Optimal uniformity is essential to minimize the formation of thermal gradients during the cooling process. Excessive thermal gradients may lead to increasing distortion control problems and even cracking. Tensi has reported that rewetting measurements are easily obtained either by measuring the conductivity profile during cooling or by measuring thermal gradients using a multiple-thermocouple probe $[19,20]$. Although the conductivity method works well for aqueous systems, its value for measuring the rewetting of petroleum oils is limited. For characterizing the rewetting properties of hydrocarbon fluids such as petroleum or vegetable oil-based quenching fluids, a multiple-thermocouple probe such as the "Tensi probe" may be used $[16,19,21]$. (The multiple-thermocouple Tensi probe is illustrated in Fig. 1 and is described in the "Experimental" section.)

For the results described herein, the quenching, rewetting, and heat transfer (heat flux) properties obtained from cooling curves obtained the multiple-thermocouple Tensi probe for a series of vegetable oils: canola, coconut, corn, cottonseed, palm, peanut, soybean, and sunflower oils. These vegetable oils were selected because they are commonly available in North and South America. The results include cooling curve parameterization, rewetting observations, and heat flux were calculated using Data Envelopment Analysis methodology. The specific computational methodology used for this work is also described here.

FIG. 1 Schematic illustration of the Tensi probe assembly used for this work.

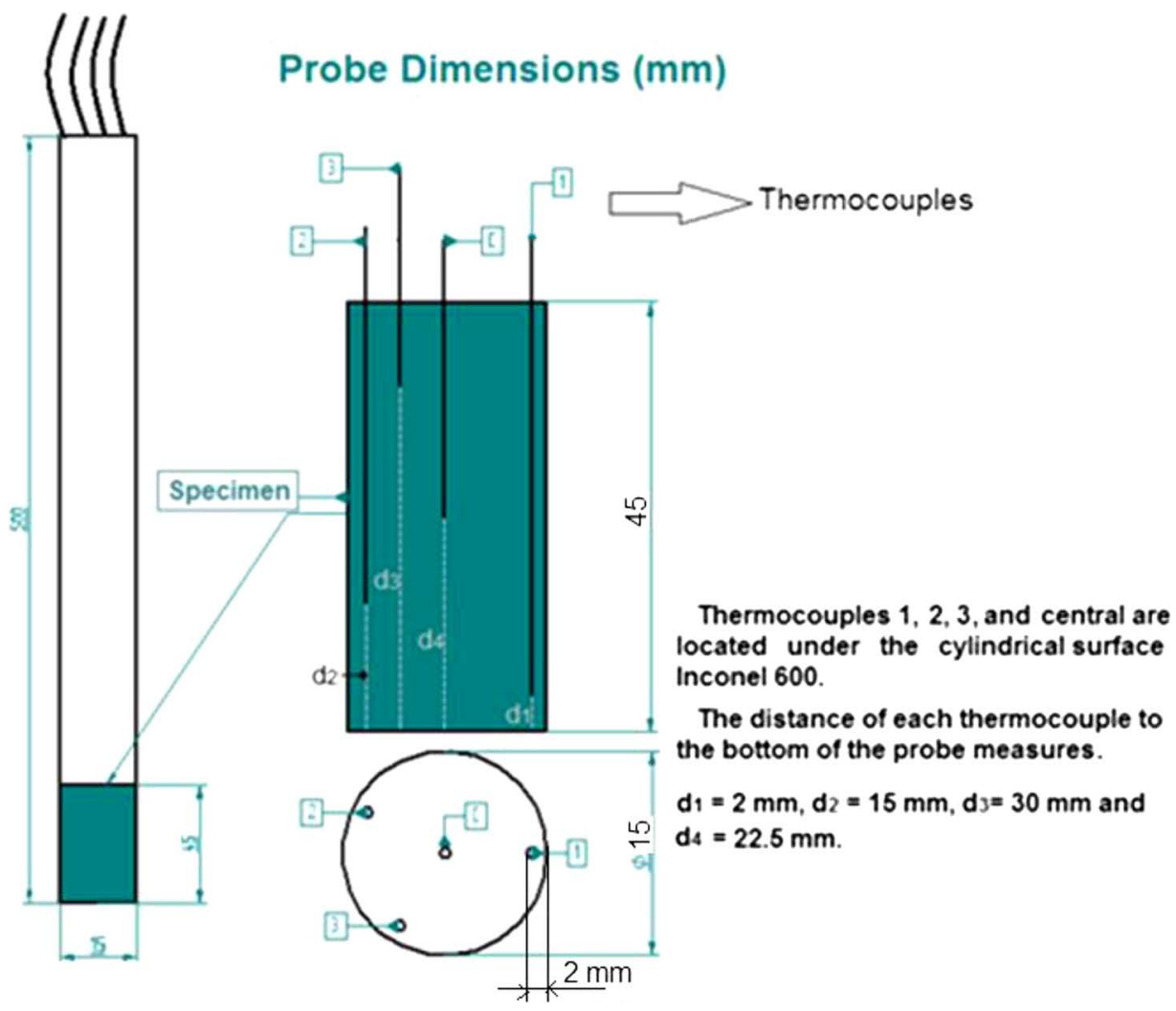




\section{Experimental}

The vegetable oils used for this work were purchased at the local market in São Carlos, Brazil and were used in the as-purchased condition without the addition of antioxidants. The quenching performance of these oils was compared to two commercially available quenching oils: Houghto-Quench 100 (a conventional "slow" oil) and Houghto-Quench KM (an accelerated "fast" oil).

Kinematic viscosity was measured at $40^{\circ} \mathrm{C}$ and $100^{\circ} \mathrm{C}$ according to ASTM D445-17a, Standard Test Method for Kinematic Viscosity of Transparent and Opaque Liquids (and Calculation of Dynamic Viscosity) [22]. The viscosity index (VI) was determined from the kinematic viscosities at $40^{\circ} \mathrm{C}$ and $100^{\circ} \mathrm{C}$ according to ASTM D2270-10, Standard Practice for Calculating Viscosity Index from Kinematic Viscosity at $40^{\circ} \mathrm{C}$ and $100^{\circ} \mathrm{C}$ [23].

Cooling curves were obtained under unagitated conditions, according to ASTM D6200-01, Standard Test Method for Determination of Cooling Characteristics of Quench Oils by Cooling Curve Analysis, at a bath temperature of $60^{\circ} \mathrm{C}$ [24]. However, instead of the standard $12.5-\mathrm{mm}$ diameter by $60-\mathrm{mm}$ cylindrical Inconel 600 assembly specified in D6200, a multiple-thermocouple probe assembly (Tensi probe) shown in Fig. 1 was used. After heating the Tensi probe in a furnace to $850^{\circ} \mathrm{C}\left(1,562^{\circ} \mathrm{F}\right)$, it was then manually and rapidly immersed into an unagitated $2,000 \mathrm{~mL}$ of the oil to be tested, which was contained in a tall-form stainless steel beaker. The probe cooling temperature and cooling times were obtained at a data acquisition rate of $8 \mathrm{~Hz}$, saved on disk storage, and used to establish a cooling temperature versus time curve. (This temperature-time data file was also used for the computational work described below).

From the cooling curves obtained for the center thermocouple, the following critical parameters were obtained. See Fig. 2 for typical quenchant characterization parameters:

(1) Film boiling to nucleate boiling transition time(s) $\left(t_{\mathrm{A}-\mathrm{B}}\right)$

(2) Temperature of film boiling to nucleate boiling transition $\left({ }^{\circ} \mathrm{C}\right)\left(T_{\mathrm{A}-\mathrm{B}}\right)$

(3) Film boiling to nucleate boiling transition cooling rate $\left({ }^{\circ} \mathrm{C} / \mathrm{s}\right)\left(C R_{D H \min }\right)$

FIG. 2

Critical cooling curve parameters.

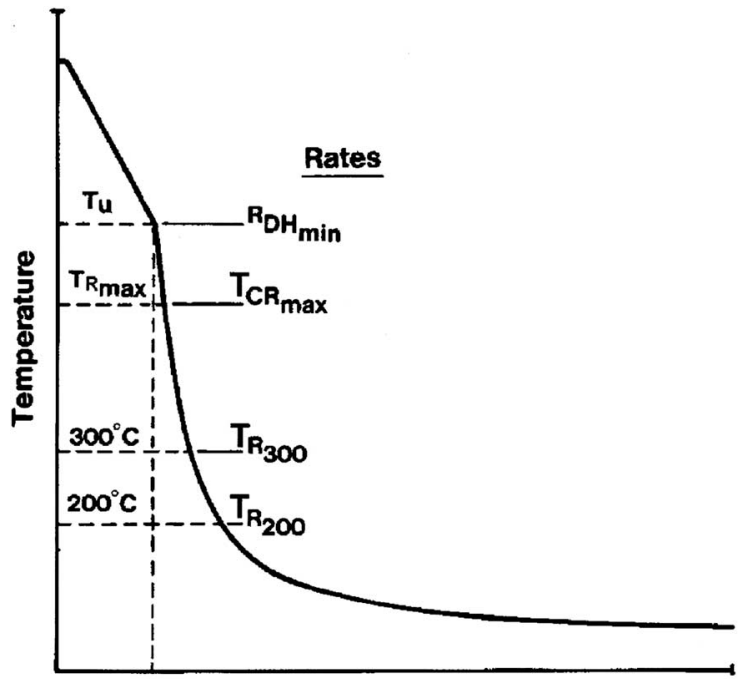


(4) Cooling rate at $700^{\circ} \mathrm{C}\left({ }^{\circ} \mathrm{C} / \mathrm{s}\right)\left(C R_{700}\right)$

(5) Maximum cooling rate $\left({ }^{\circ} \mathrm{C} / \mathrm{s}\right)\left(C R_{\max }\right)$

(6) Temperature of the maximum cooling rate $\left({ }^{\circ} \mathrm{C}\right)\left(T_{C R \max }\right)$

(7) Cooling rate at $300^{\circ} \mathrm{C}\left({ }^{\circ} \mathrm{C} / \mathrm{s}\right)\left(C R_{300}\right)$

(8) Time to cool to $300^{\circ} \mathrm{C}(\mathrm{s})\left(t_{300}\right)$

(9) Cooling rate at $200^{\circ} \mathrm{C}\left({ }^{\circ} \mathrm{C} / \mathrm{s}\right)\left(C R_{200}\right)$

(10) Time to cool to $200^{\circ} \mathrm{C}(\mathrm{s})\left(t_{200}\right)$

Parameters 1-3 are related to the full film boiling (vapor blanket cooling) to nucleate boiling transition time and the temperature and cooling rate at critical temperatures. The cooling rate at $700^{\circ} \mathrm{C}$, Parameter 4 , is measured since it is usually desirable to maximize this cooling rate to avoid the steel pearlite transformation region. Parameters 5 and 6 are the maximum rate of cooling and temperature where this occurs. Generally, it would be desirable to maximize $C R_{\max }$ and minimize $T_{C R \max }$. The rate of cooling at temperatures, such as $200^{\circ} \mathrm{C}$ and $300^{\circ} \mathrm{C}$, Parameters 7 and 9 , are also determined, since they are related to the potential for steel cracking and distortion. To minimize these problems, it is desirable to minimize cooling rates in this region. Parameters 8 and 10 are related to regions of martensite transformation. It is generally desirable to minimize these parameters.

\section{Computational Methodology}

\section{PRINCIPLE ANALYSIS OF INVERSE HEAT CONDUCTION PROBLEM}

\section{Calculation and Derivation of Sensitivity Coefficient}

To show the sensitivity extent to the temperature measurement in internal points, the sensitivity coefficient is defined as the first derivative of temperature to surface heat flux. See the following:

$$
X_{M}(x, t)=\frac{\partial T(x, t)}{\partial Q_{M}}
$$

The sensitivity coefficient can be calculated from the partial differential equation, which is derived from the transient heat conduction equation, boundary condition, and initial condition by differentiating them with respect to $Q_{M}$. See the following:

Temperature Field, $T$ Sensitivity Coefficient, $X$

$$
\begin{aligned}
& \rho C_{p} \frac{\partial T}{\partial t}=\frac{\partial}{\partial x}\left[k \frac{\partial T}{\partial x}\right] \\
& \text { partial differential equation } \rho C_{p} \frac{\partial X_{M}}{\partial t}=\frac{\partial}{\partial x}\left[k \frac{\partial X_{M}}{\partial x}\right] \\
& -\left.k \frac{\partial T}{\partial x}\right|_{x=0}=\left\{\begin{array}{cc}
\text { const } & t_{M-1}<t<t_{M} \\
q(t) & t>t_{M}
\end{array}\right. \\
& \text { boundary condition }-\left.k \frac{\partial X_{M}}{\partial x}\right|_{x=0}=\left\{\begin{array}{cc}
1 & t_{M-1}<t<t_{M} \\
0 & t>t_{M}
\end{array}\right. \\
& -\left.k \frac{\partial T}{\partial x}\right|_{x=L}=0
\end{aligned}
$$




$$
\begin{gathered}
\text { boundary condition } \quad-\left.k \frac{\partial X_{M}}{\partial x}\right|_{x=L}=0 \\
T\left(x, t_{M-1}\right)=T_{M-1}(x) \\
\text { initial condition } \quad X_{M}\left(x, t_{M-1}\right)=0
\end{gathered}
$$

where $t_{M-1}$ is the time at the beginning of the heat flux step and $T_{M-1}(x)$ is the temperature distribution of time $t_{M-1}$. What is known, during $t_{M-1}$ and $t_{M}$, is that heat flux is considered a constant. An important conclusion that can be drawn from the aforementioned equation is that the same differential equation is given for $X_{M}(x, t)$, as for $T(x, t)$. Because of this similarity between $T(x, t)$ and $X_{M}(x, t)$ problems, the same computer program of a finite difference method can be used for both $T(x, t)$ and $X_{M}(x, t)$ solutions.

\section{Calculation of Surface Heat Flux}

Firstly, the surface heat flux was considered as a constant during $t_{M-1}$ and $t_{M}$. The temperature field $T(x, t)$ depends on the unknown surface heat flux $Q_{M}$ in a continuous manner. This dependence is written as $T\left(x, t, t_{M-1}, Q_{M-1}, Q_{M}\right)$, wherein $Q_{M-1}$ is the vector containing all preceding surface heat flux values $Q_{1}, Q_{2}, Q_{3} \ldots \ldots \ldots \ldots Q_{M-1}, t_{M-1}$, which indicates the time that the surface heat flux begins. $T\left(x, t, t_{M-1}, Q_{M-1}, Q_{M}\right)$ can be expanded in a Taylor series at an arbitrary value of surface heat flux $Q^{*}$, only the first derivative is nonzero; thus the following is the exact result for location at time $t_{M}$ :

$$
T\left(x, t, t_{M-1}, Q_{M-1}, Q_{M}\right)=T\left(x, t, t_{M-1}, Q_{M-1}, Q^{*}\right)+\left(Q_{M}-Q^{*}\right) \cdot X\left(x, t, t_{M-1}, Q_{M-1}\right)
$$

where $X\left(x, t, t_{M-1}, Q_{M-1}\right)=\left.\frac{\partial X\left(x, t, t_{M-1}, Q_{M-1}, Q_{M}\right)}{\partial Q_{M}}\right|_{Q_{M}=Q^{*}}$.

To avoid the much bigger error of temperature measurement on a single point, multiple sensors are recommended. If there are J sensors, then the least square error is defined as follows:

$$
S=\sum_{K=1}^{J}\left[\bar{T}_{K, M}-T\left(x, t, t_{M-1}, Q_{M-1}, Q_{M}\right)\right]^{2}
$$

where $\bar{T}_{K, M}$ are the measurement value at the time that the surface heat flux begins.

Differentiating Eq 11 with respect to $Q_{M}$ gives the following:

$$
\frac{\partial S}{\partial Q_{M}}=2 \cdot \sum_{K=1}^{J}\left[\bar{T}_{K, M}-T\left(x_{K}, t, t_{M-1}, Q_{M-1}, Q_{M}\right)\right] \cdot X_{K, M}=0
$$

An arbitrary value of surface heat flux $Q^{*}$ is assumed, and the temperature of internal point $T\left(x_{K}, t, t_{M-1}, Q_{M-1}, Q_{M}\right)$ can be expanded as a Taylor series on time $t_{M}$, as follows:

$$
T\left(x_{K}, t, t_{M-1}, Q_{M-1}, Q_{M}\right)=T_{K, M}^{*}+\left(Q_{M}-Q^{*}\right) \cdot X_{K, M}
$$

Substituting Eq 13 into Eq 12 gives the following:

$$
Q_{M}=Q^{*}+\frac{\sum_{K=1}^{J}\left[\bar{T}_{K, M}-T_{K, M}^{*}\right] \cdot X_{K, M}}{\sum_{K=1}^{J}\left(X_{K, M}\right)^{2}}
$$




\section{Calculation of Surface Heat Flux $\mathbf{h}_{\Sigma}$}

The surface heat flux $Q_{M}$ is calculated, and at the same time, the temperature distribution of the component (including boundary) is also known. $\mathrm{h}_{\Sigma}$ can be calculated according to Newton's law of heat transfer:

$$
\mathrm{h}_{\Sigma}=\frac{Q_{M}}{\left(T_{s}-T_{\infty}\right)}
$$

where $Q_{M}$ is the surface heat flux of component, $T_{s}$ is the surface temperature of component, and $T_{\infty}$ is the temperature of quenchants.

\section{ALGORITHM OF INVERSE HEAT CONDUCTION PROBLEM}

According to Eq 14, which gives the basic algorithm of inverse heat conduction problem:

(1) Assume the surface heat flux in Eq $4 Q^{*}=0$ on $t_{M}$. Use the heat conduction partial difference Eq 2 and boundary condition Eqs 6 and 8 to calculate the temperature distribution;

(2) According to Eqs 9, 5, 7, and 3, calculate the sensitivity coefficient $X_{K, M}$;

(3) According to the known temperature on one or more inside points, calculate the heat flux $Q_{M}$ during $t_{M-1}$ and $t_{M}$ by using Eq 14;

(4) Replacing $Q^{*}$ with $Q_{M}$, return to Step (1) and recalculate until the difference between $Q^{*}$ with $Q_{M}$ is less than specific tolerance $\varepsilon$;

(5) Calculate the value of $h_{\Sigma}$ between the time step $t_{M-1}$ and $t_{M}$; and

(6) Repeat these steps from (1) to (5) to get all the values of $h_{\Sigma}$ during the whole quenching process and the $h_{\Sigma}-T$ curve.

Fig. 3 is the flow chart of the $h_{\Sigma}$ calculation program according to the described algorithm.

\section{Discussion and Results}

\section{VEGETABLE OIL VISCOSITY}

Fluid viscosity is an important contributing factor to the interfacial heat transfer between a hot surface and a cooler body of fluid. Typically, all other factors being equal, such as fluid flow and turbulence, fluid type, etc., heat transfer rates increase as fluid viscosity increases. Therefore, it is important to assess fluid viscosity when considering the relative impact of different vegetable oils on quenching performance. This was done for this work by comparing kinematic viscosities (ASTM D445) at $40^{\circ} \mathrm{C}$ and $100^{\circ} \mathrm{C}$.

Since viscosity varies with temperature, it is of value to obtain a measurement of the sensitivity of a fluid to temperature variation. For industrial fluids, a common measure of assessing the temperature sensitivity of viscosity is to determine the VI by ASTM D2270. VI is a method for quantifying the relative change of viscosity with temperature. The lower the VI, the greater the change of viscosity, with respect to temperature. The VIs of the vegetable oils discussed in this work were determined for comparison to each other and the petroleum oil quenchants utilized in this work.

As Table 1 shows, the kinematic viscosities at $40^{\circ} \mathrm{C}$ for the vegetable oils used for this work were generally similar, with an average of $33.78 \mathrm{cSt}$, with coconut oil being the lowest (27.94 cSt) and peanut oil being the highest (38.83). The average viscosities for all vegetable 
FIG. 3

Flow chart of the $h_{\Sigma}$ calculation program.

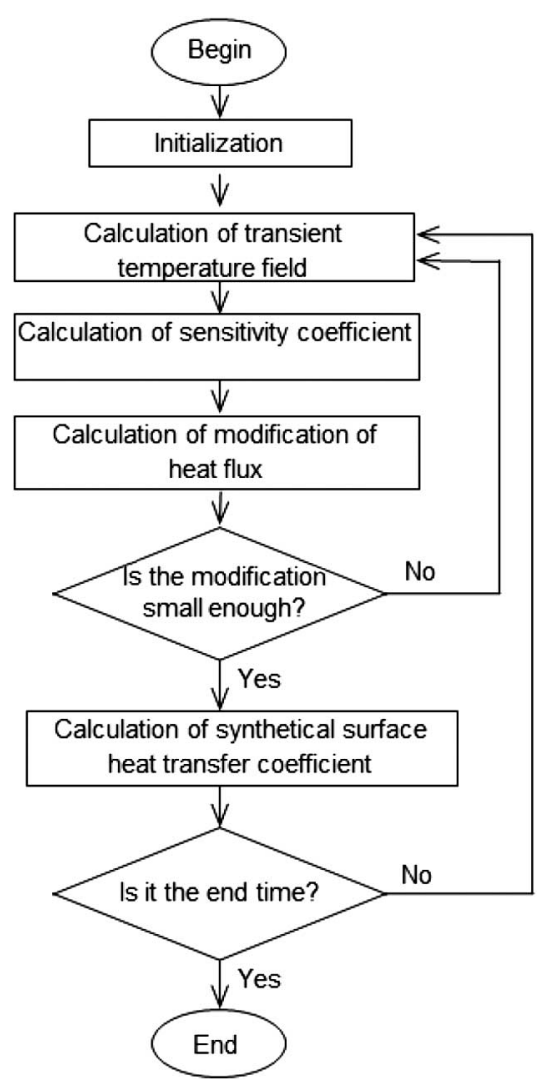

oils at $100^{\circ} \mathrm{C}$ was $7.87 \mathrm{cSt}$, again with coconut oil exhibiting the lowest viscosity (6.42 cSt) and peanut oil exhibiting the highest viscosity $(8.60 \mathrm{cSt})$.

Importantly, the viscosities at $40^{\circ} \mathrm{C}$ of all of the vegetable oils, which possess a triglyceride (tri-fatty ester) structure significantly greater than either the "fast" or "conventional" petroleum oil quenchants, which were $13.72 \mathrm{cSt}$ and $19.52 \mathrm{cSt}$, respectively. Not surprisingly, the "fast" petroleum oil exhibited a lower viscosity than the "conventional" oil, since the heat transfer would be expected to be faster with a lower viscosity on the basis of oil viscosity alone. With lower viscosities, one would expect both petroleum oil quenchants to exhibit faster cooling rates than any of the vegetable oils. However, other determining factors must be considered, such as temperature-dependent thermal conductivity and specific heat capacity [25].

Table 1 shows that the VI values for all of the vegetable oils which possess a triglyceride (ester) structure are approximately two times greater than the VI value for either petroleum oil quenchant, indicating that the viscosities of the vegetable oils, as a class, do not exhibit the same degree of decrease with increasing temperature as would be expected from the petroleum oil quenchants.

\section{REWETTING CHARACTERISTICS}

One method of observing the rewetting characteristics of a quenchant is to compare the surface cooling curves at different axial positions obtained on a test piece, such as the Tensi 
TABLE 1

Kinematic viscosity and VI determined for all vegetable oils and petroleum oil-based quenchants.

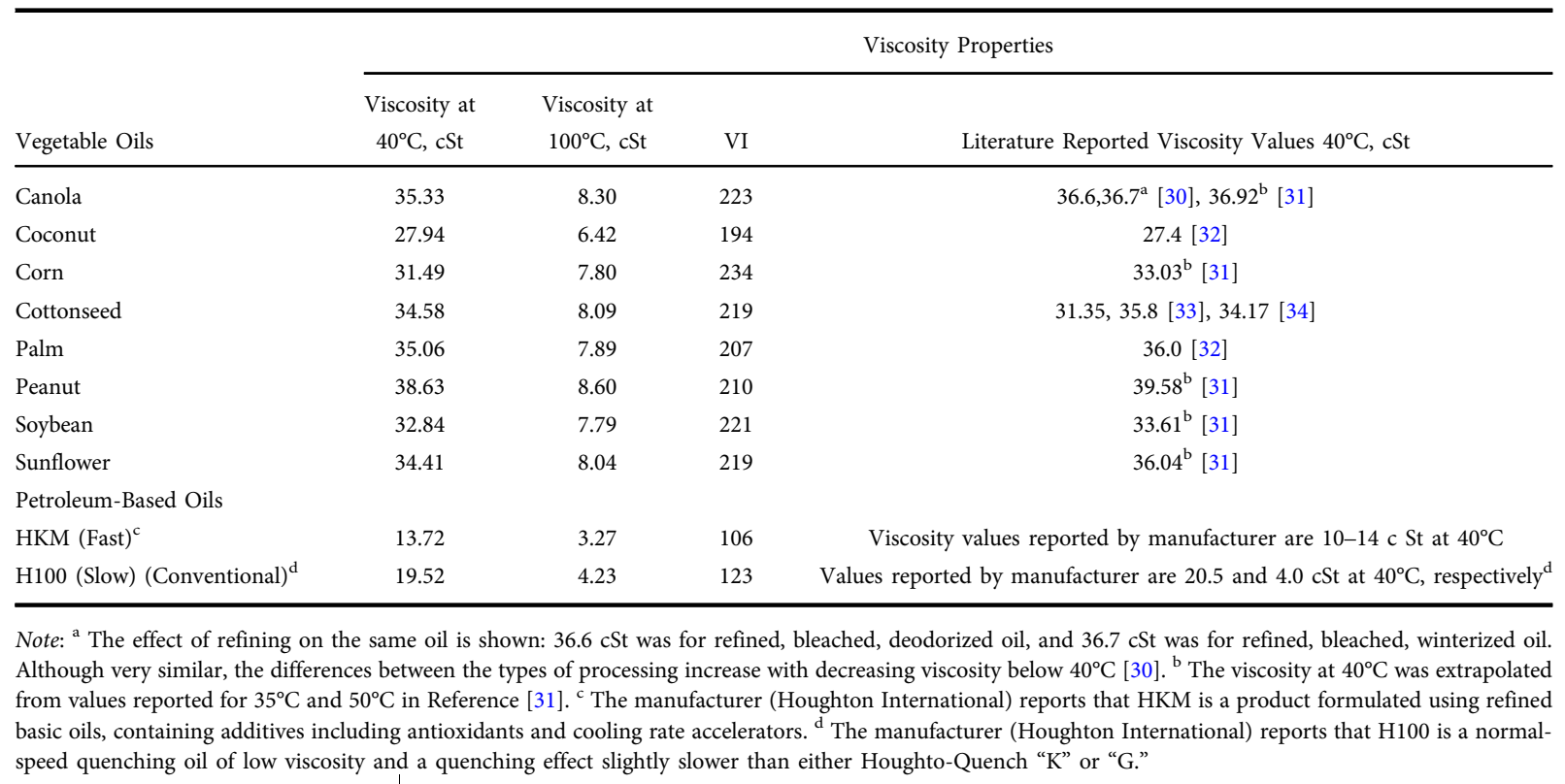

probe, throughout the quenching cycle. If perfectly uniform cooling behavior is obtained over the entire surface when immersion quenching the probe, then all of the surface cooling curves will be identical or nearly identical, and typically, only convective cooling will be observed. However, if there is a moving wetting front on the surface during cooling, the rewetting behavior will be reflected by the transition from film boiling to nucleate boiling and nucleate boiling to convective cooling. Nonuniform cooling results in the generation of thermal gradients, which may lead to increased distortion and possibly cracking. Therefore, the rewetting behavior of a quenchant is an important quenching variable.

The cooling time-temperature and cooling rate curves obtained for all of the vegetable oils and petroleum oil quenchants discussed here, using the multiple-thermocouple Tensi probe shown in Fig. 1, are provided in Figs. 4-13 and summarized in Table 2.

It would be expected that quenching uniformity would increase as film boiling decreases. Ideally, only convective heat transfer would occur on the probe surface. Of the various vegetable oil cooling curves summarized in Table 2, the surface cooling curves for palm oil (see Fig. 7) showed very pronounced extension of the expected region consistent with the presence of film boiling. This behavior was much greater than that observed for any of the other vegetable oils evaluated. On the other hand, coconut oil, the lowest molecular weight vegetable oil evaluated, exhibited minimal evidence of film boiling based on its cooling curve behavior (see Fig. 5). In view of the apparent film-boiling behavior suggested by the cooling curve for palm oil, it might be expected that the lowest molecular weight vegetable oil evaluated, coconut oil, would exhibit even greater apparent filmboiling behavior, since vapor pressure would be expected to increase as molecular weight decreases. However, this was not observed.

The other vegetable oil that showed some, although also minimal, evidence of film boiling was canola oil (see Fig. 4). The apparent film-boiling behavior of the remaining vegetable oils, corn, cottonseed, peanut, soybean, and sunflower (see Figs. 6, 7, and 9-11), 
FIG. 4

(a) Cooling time-temperature curve for canola oil at $60^{\circ} \mathrm{C}$, no agitation (using Tensi probe).

(b) Cooling rate curve for canola oil at $60^{\circ} \mathrm{C}$, no agitation (using Tensi probe).

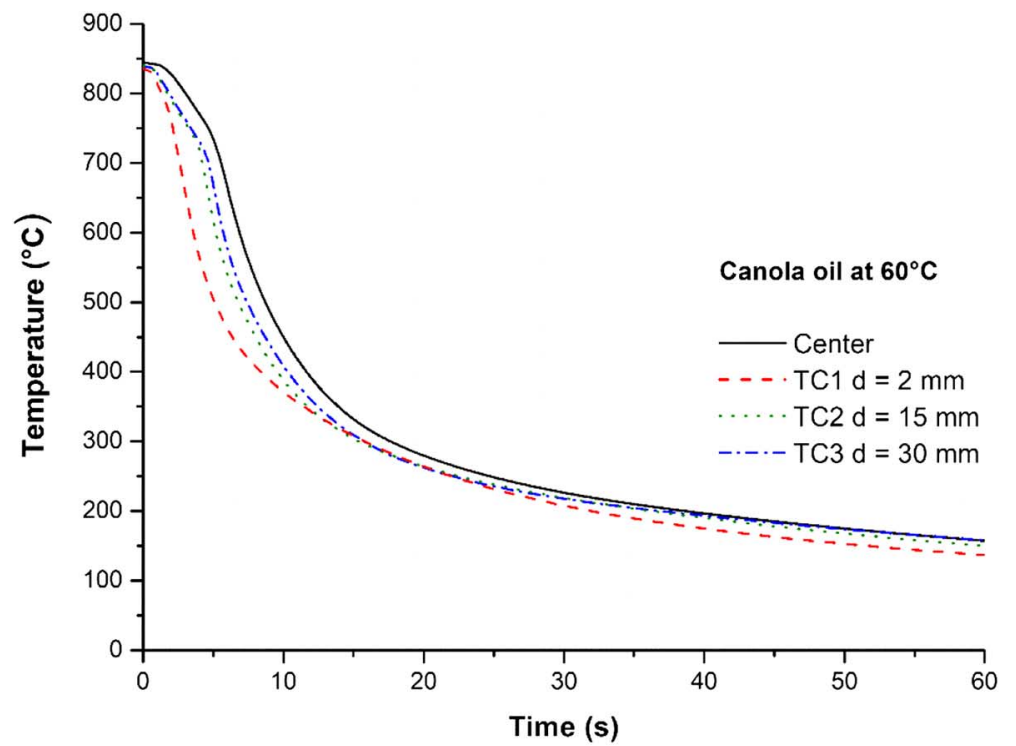

(a)

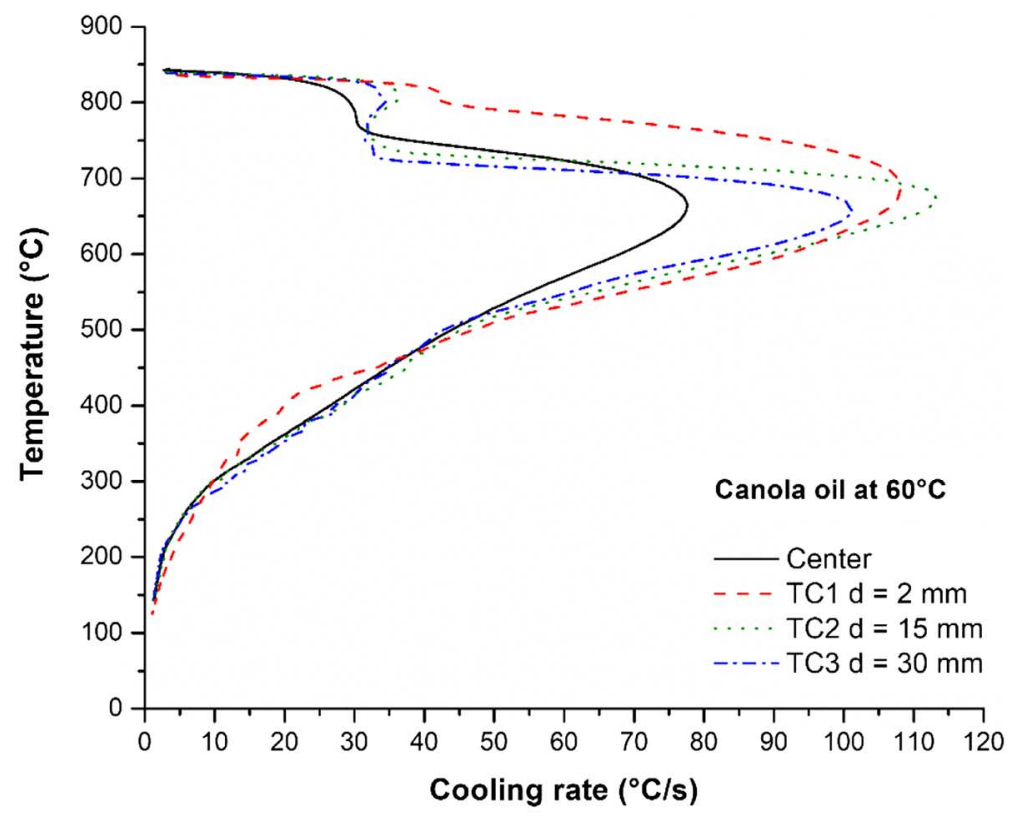

(b)

exhibited very little evidence of film boiling. Of these remaining vegetable oils, peanut oil exhibited the least evidence of film boiling.

It is very important to put the results shown for vegetable oils in context, because vegetable oils (if present in "pure" triglyceride oil) do not boil. The highest cooking (use) temperature for a vegetable oil is limited by the temperature at which the oil begins to smoke. Typical smoke points for common vegetable oils may vary from $121^{\circ} \mathrm{C}$ to $>232^{\circ} \mathrm{C}$ $\left(250^{\circ} \mathrm{F}\right.$ to $\left.>450^{\circ} \mathrm{F}\right)$. The exact smoke points cannot be cited because of the normal 
FIG. 5

(a) Cooling time-temperature curve for coconut oil at $60^{\circ} \mathrm{C}$, no agitation (using Tensi probe).

(b) Cooling rate curve for coconut oil at $60^{\circ} \mathrm{C}$, no agitation (using Tensi probe).

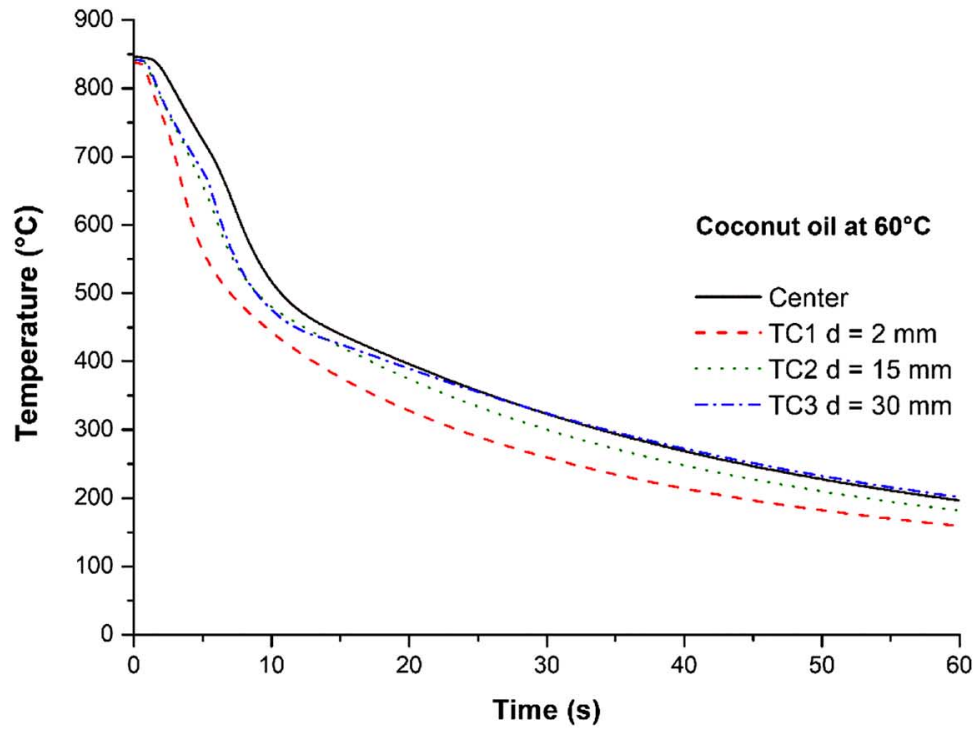

(a)

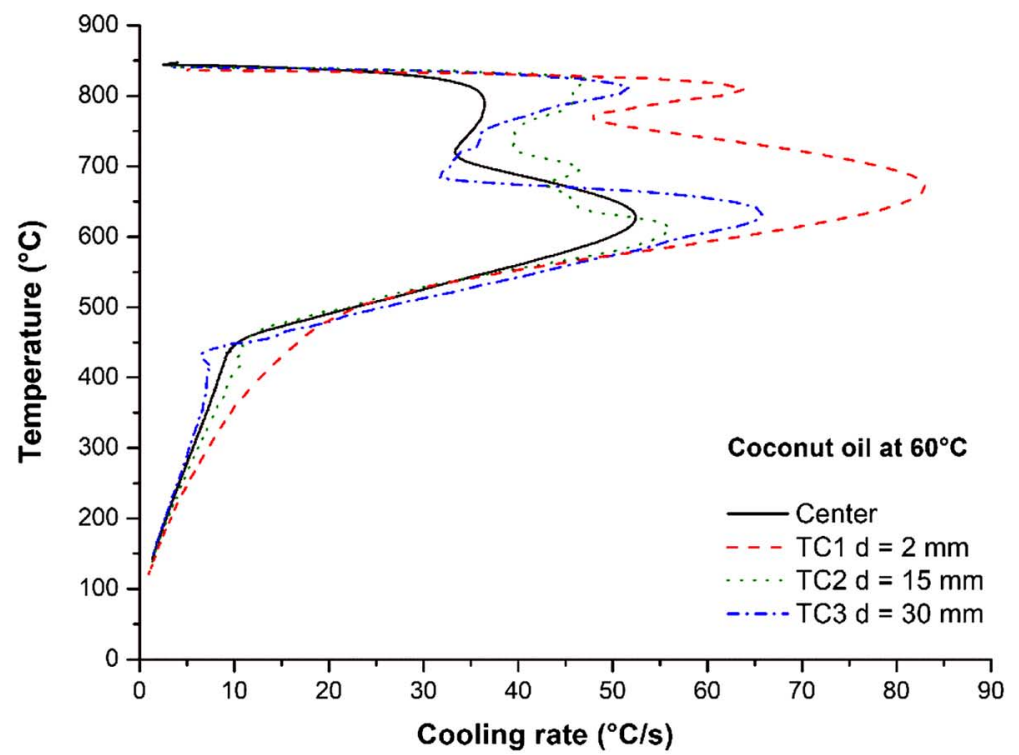

(b)

compositional variation, refining method, seed variety, and even the climate and weather during the plant's growing season. However, typical smoke points for common vegetable oils are safflower oil, $163^{\circ} \mathrm{C}-177^{\circ} \mathrm{C}\left(325^{\circ} \mathrm{F}-350^{\circ} \mathrm{F}\right)$; corn oil, $204^{\circ} \mathrm{C}-213^{\circ} \mathrm{C}\left(400^{\circ} \mathrm{F}-415^{\circ} \mathrm{F}\right)$; peanut oil, $216^{\circ} \mathrm{C}-221^{\circ} \mathrm{C}\left(420^{\circ} \mathrm{F}-430^{\circ} \mathrm{F}\right)$; cottonseed oil, $218^{\circ} \mathrm{C}-227^{\circ} \mathrm{C}\left(425^{\circ} \mathrm{F}-440^{\circ} \mathrm{F}\right)$; canola oil, $224^{\circ} \mathrm{C}-229^{\circ} \mathrm{C}\left(435^{\circ} \mathrm{F}-445^{\circ} \mathrm{F}\right)$; and sunflower and soybean oils, $227^{\circ} \mathrm{C}-232^{\circ} \mathrm{C}$ $\left(440^{\circ} \mathrm{F}-450^{\circ} \mathrm{F}\right)$ [26]. At atmospheric pressure and temperatures greater than the smoke point, vegetable oils degrade; they do not boil.

However, commercially available vegetable oils are not pure single-component fluids, but they contain a range of different triglyceride structures, which are dependent on the 


\section{FIG. 6}

(a) Cooling time-temperature curve for corn oil at $60^{\circ} \mathrm{C}$, no agitation (using Tensi probe).

(b) Cooling rate curve for corn oil at $60^{\circ} \mathrm{C}$, no agitation (using Tensi probe).

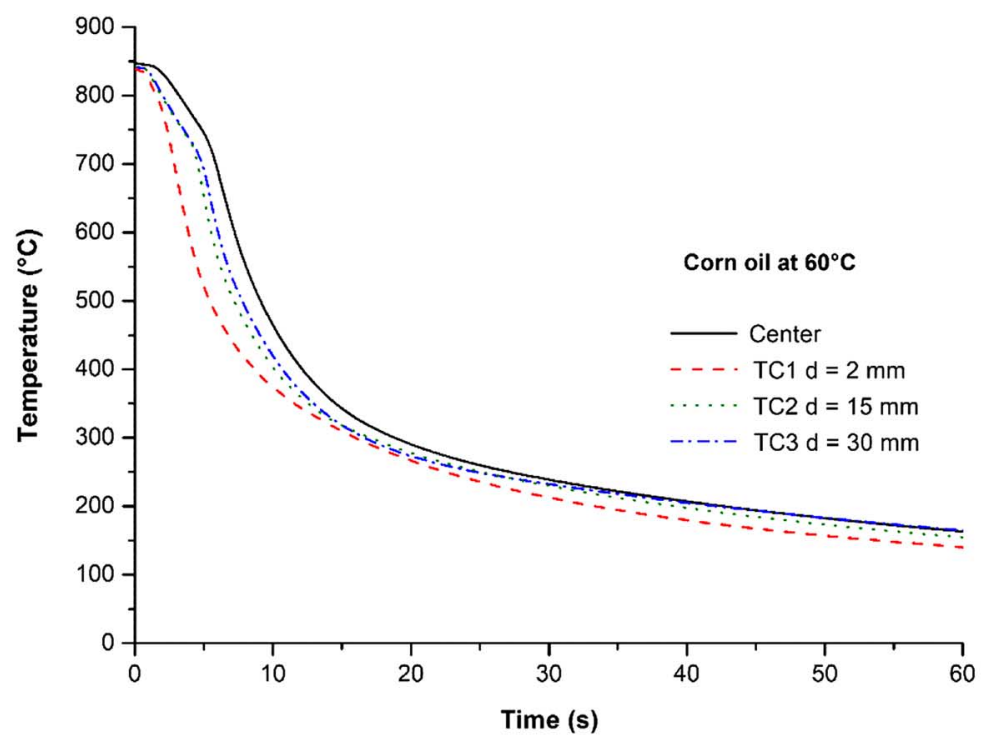

(a)

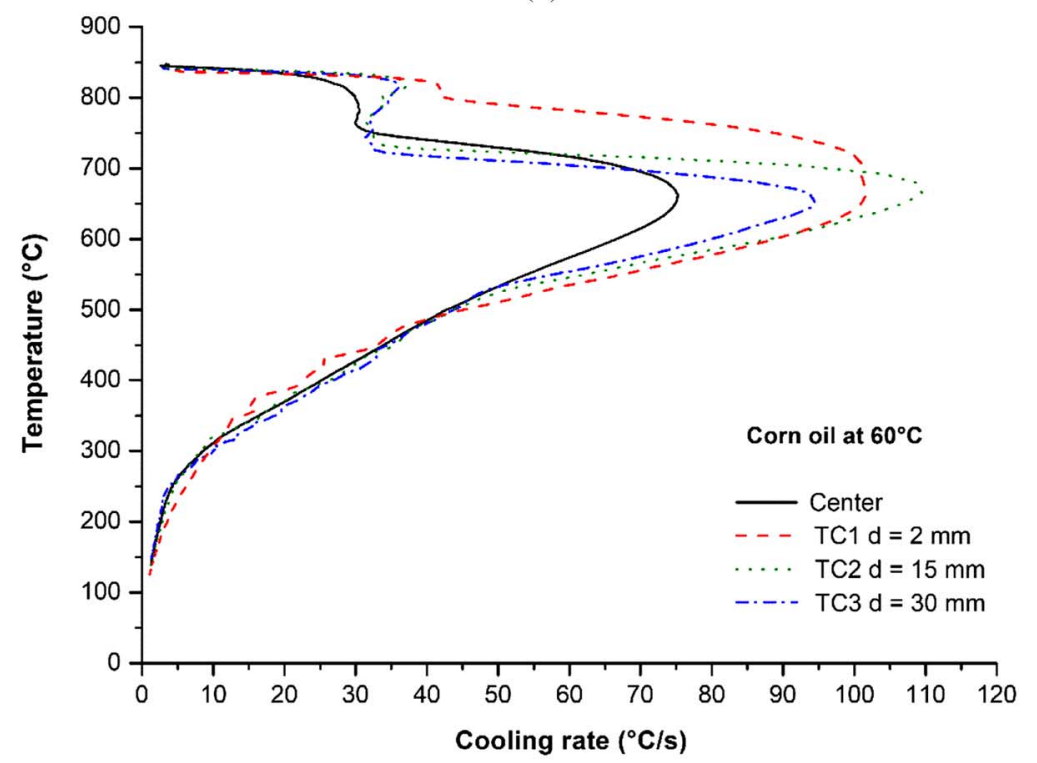

(b)

particular seed oil. Normally they are refined by a variety of possible methods, but even after refining, they may still potentially contain small quantities of by-products. In addition to monoglyceride and diglyceride structures, vegetable oils may also contain free fatty acids, tocopherols, sterols, phenolic compounds, phospholipids, and other variants, as well as low concentrations of water [27,28]. Some of these compounds contribute to potential volatility, which may be observed as film boiling during immersion quenching by hot steel. Unless the as-purchased vegetable oils are further purified, they all contain a number of these potential by-products at varying concentrations, depending on the refining process and its effectiveness. All of the vegetable oils reported here were used in their 


\section{FIG. 7}

(a) Cooling time-temperature curve for cottonseed oil at $60^{\circ} \mathrm{C}$, no agitation (using Tensi probe). (b) Cooling rate curve for cottonseed oil at $60^{\circ} \mathrm{C}$, no agitation (using Tensi probe).

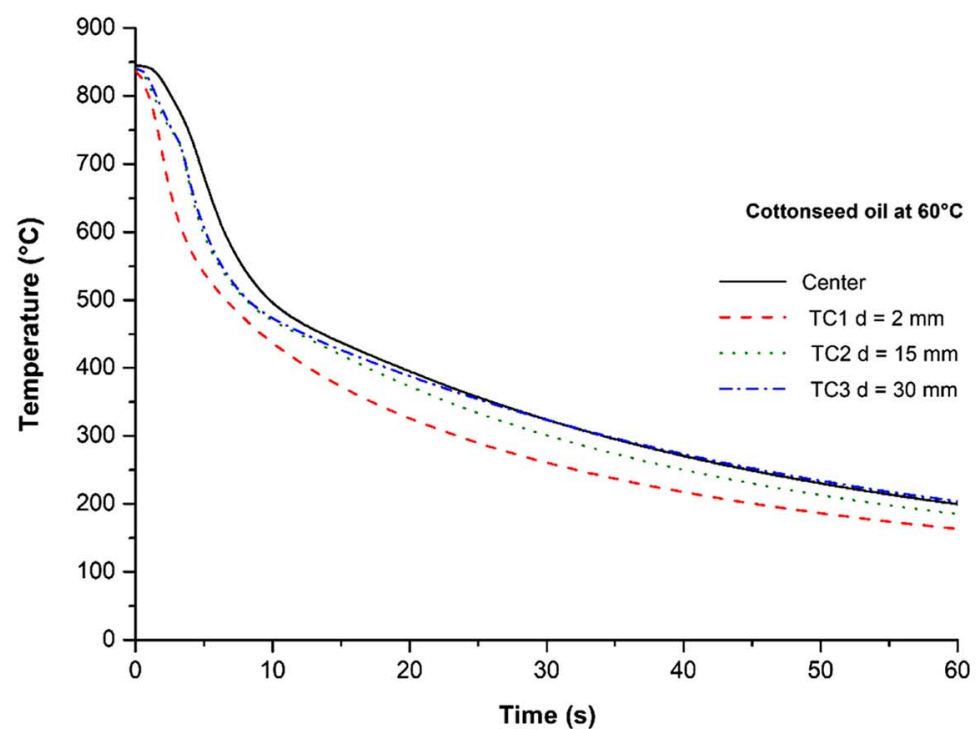

(a)

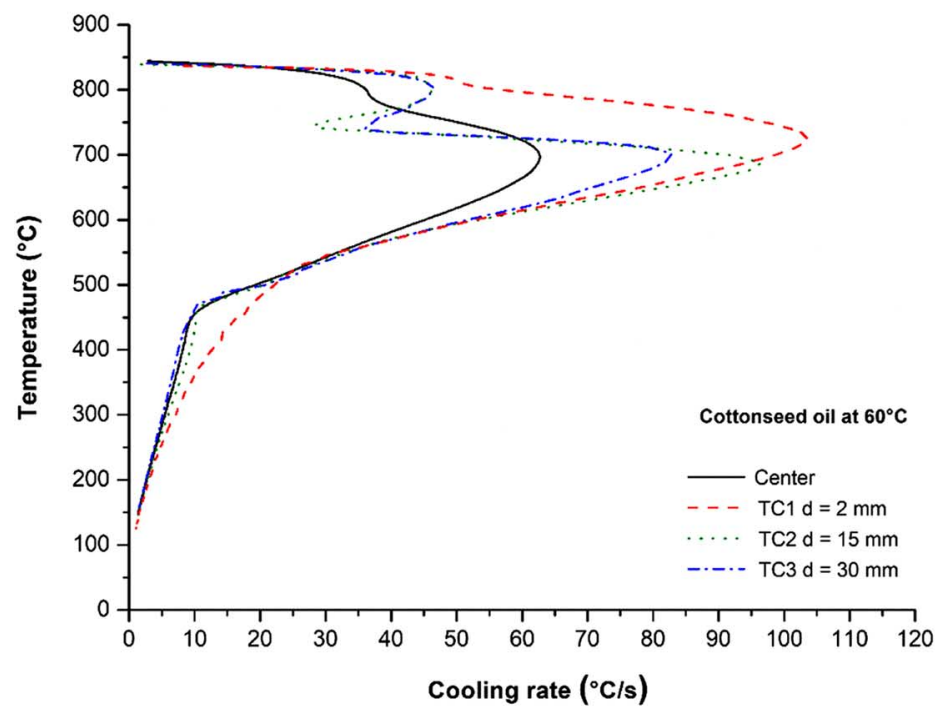

(b)

as-purchased condition. However, based on the surface cooling curves obtained using the Tensi probe, it is concluded that the palm oil used for this work contains sufficient non-triglyceride impurities to exhibit the apparent film-boiling behavior observed. Typical refining and purification practices and the composition of commercial palm oil are described in Ref. [29].

As for the actual superimposable quality of the surface cooling curves of all of the vegetable oils, the cooling curves obtained at the bottom end position $(2 \mathrm{~mm})$, as shown in

Fig. 1, were clearly the fastest of all of the cooling curves and indicated a relatively substantial end cooling effect. However, with the exception of palm oil (see Fig. 8), the 
FIG. 8

(a) Cooling time-temperature curve for palm oil at $60^{\circ} \mathrm{C}$, no agitation (using Tensi probe).

(b) Cooling rate curve for palm oil at $60^{\circ} \mathrm{C}$, no agitation (using Tensi probe).

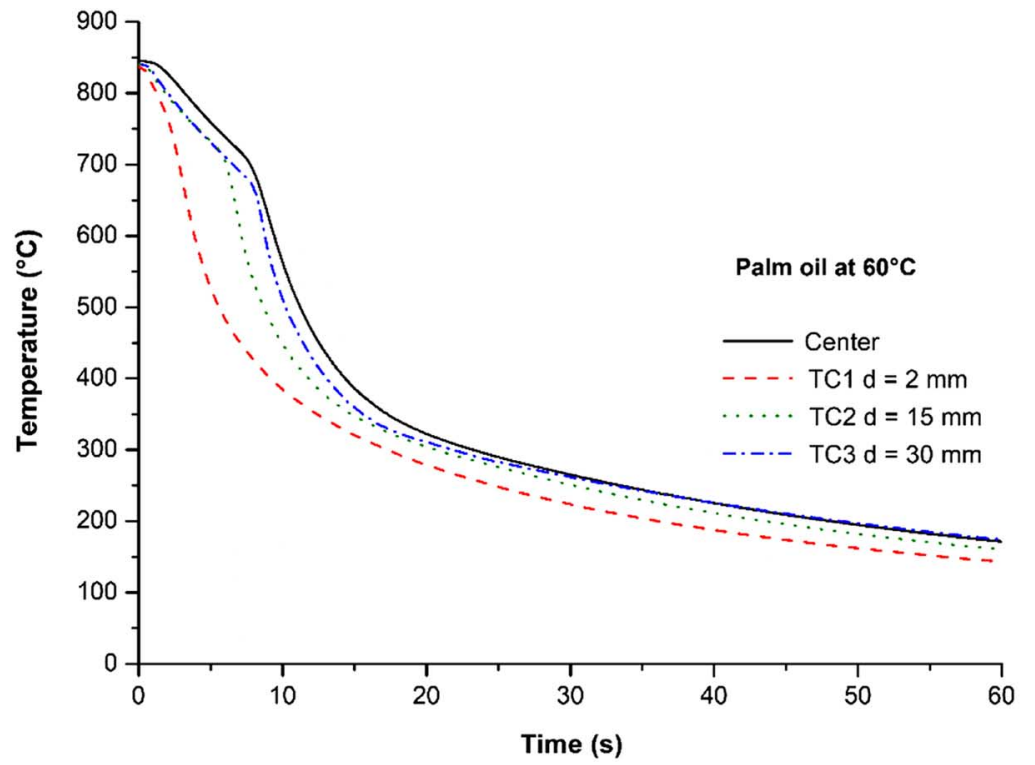

(a)

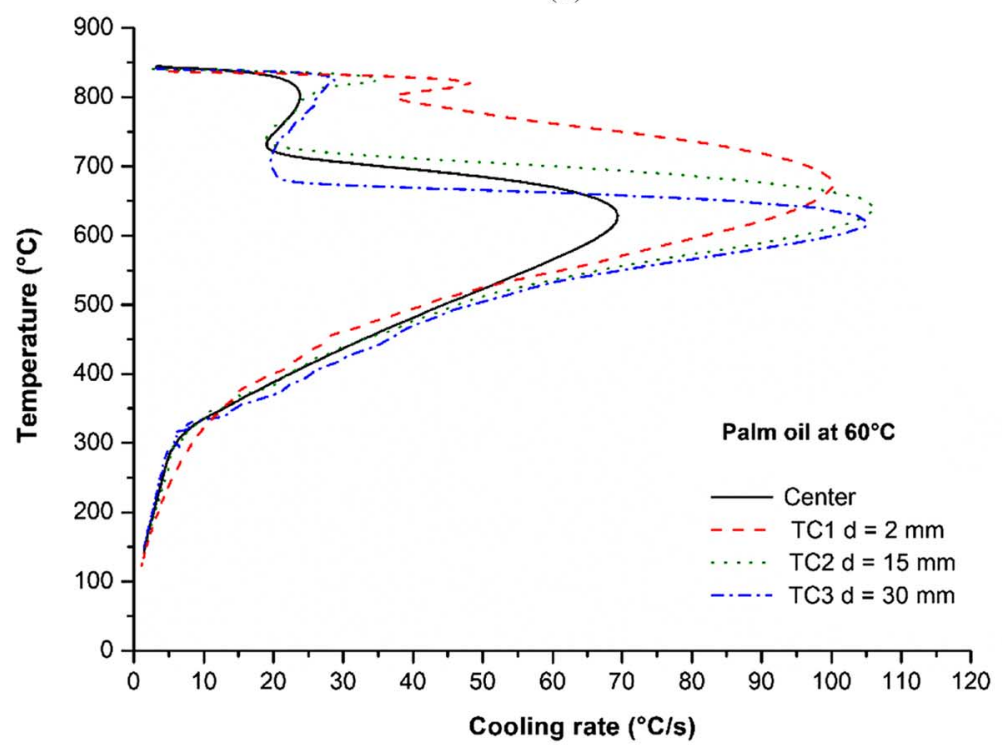

(b)

surface cooling curves for the $15-\mathrm{mm}$ and $30-\mathrm{mm}$ positions were nearly convergent, which indicates that with the exception of the end position, relatively uniform, convective cooling predominates for the other vegetable oils evaluated.

As expected, both petroleum oil quenchants, Houghto-Quench HKM "fast" oil, and Houghto-Quench H100 "conventional slow" oil (see Figs. 12 and 13, respectively) exhibited well-differentiated film-boiling regions in their cooling curve behavior. Furthermore, the surface cooling curves at each position were well-differentiated, indicating a moving wetting front during the quenching process, which is an inherently nonuniform quench relative to the surface cooling behavior shown by the vegetable oils as a group. 


\section{FIG. 9}

(a) Cooling time-temperature curve for peanut oil at $60^{\circ} \mathrm{C}$, no agitation (using Tensi probe).

(b) Cooling rate curve for peanut oil at $60^{\circ} \mathrm{C}$, no agitation (using Tensi probe).

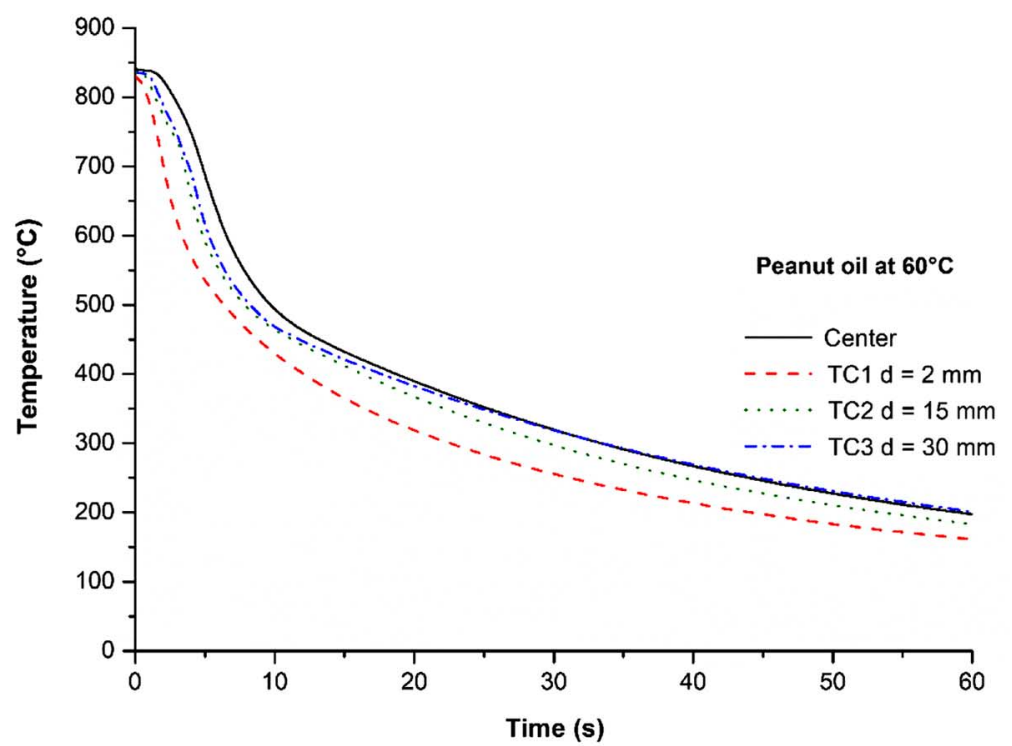

(a)

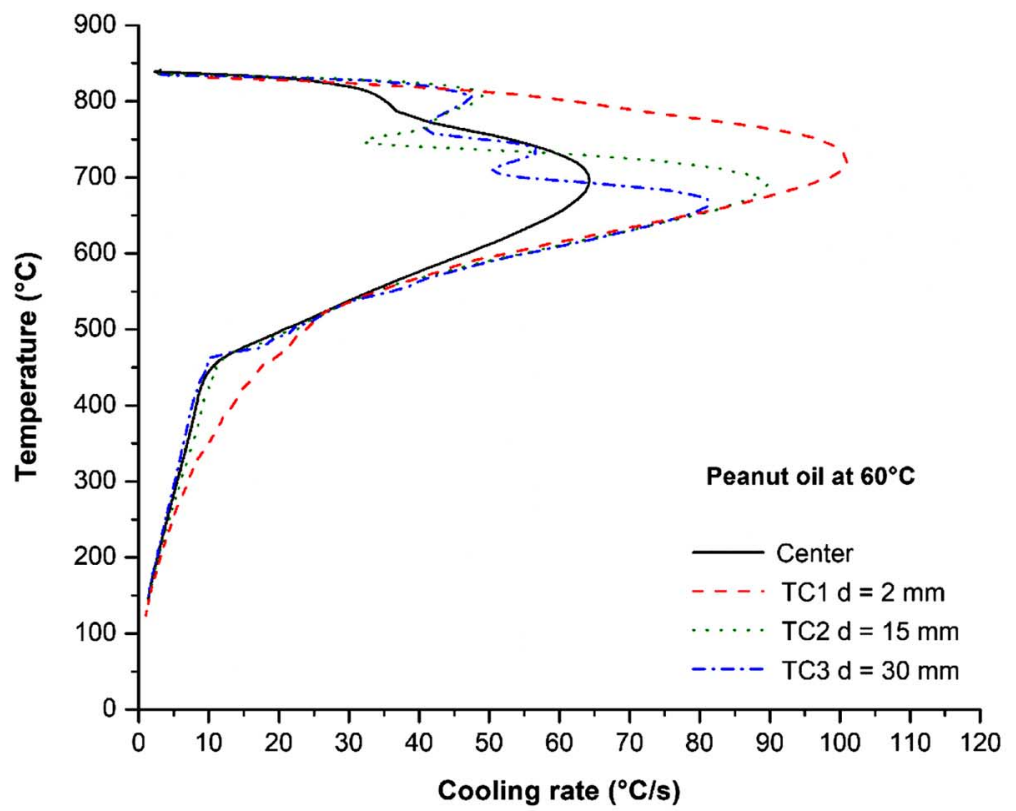

(b)

\section{DIFFERENTIATION OF COOLING PROPERTIES BY COOLING CURVE PARAMETERIZATION}

The cooling behavior of a quenchant can be differentiated and quantified by cooling curve parameterization, as described in ASTM D6200 [24] and illustrated in Fig. 2. These parameters were determined from the time-temperature cooling data obtained from the thermocouple located at the geometric center of the Tensi probe (see Fig. 1) and are summarized in Table 3. 


\section{FIG. 10}

(a) Cooling time-temperature curve for soybean oil at $60^{\circ} \mathrm{C}$, no agitation (using Tensi probe). (b) Cooling rate curve for soybean oil at $60^{\circ} \mathrm{C}$, no agitation (using Tensi probe).

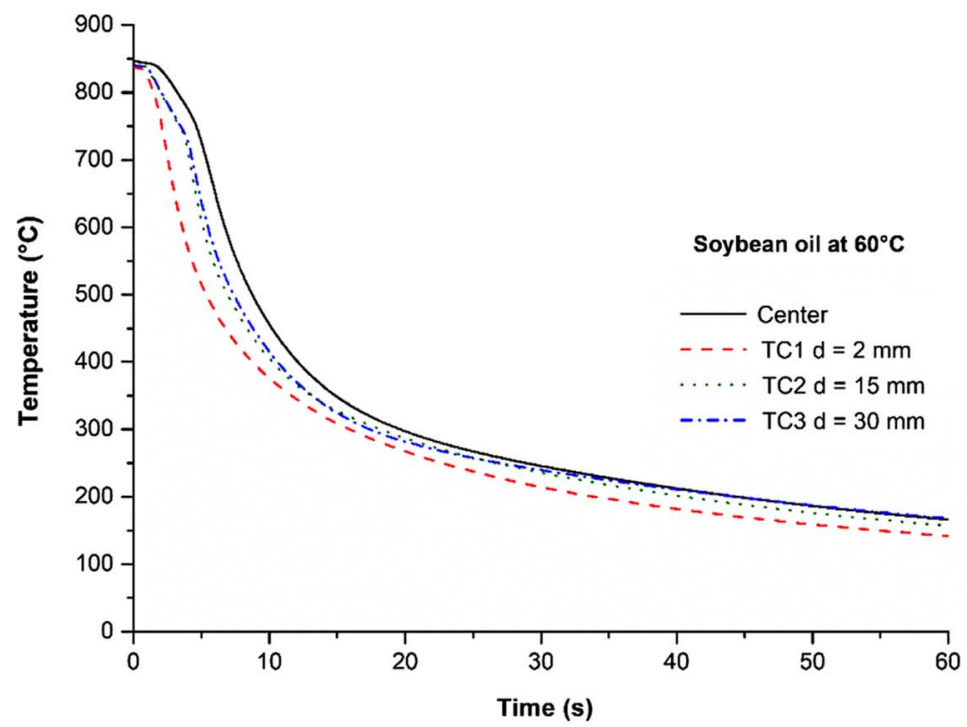

(a)

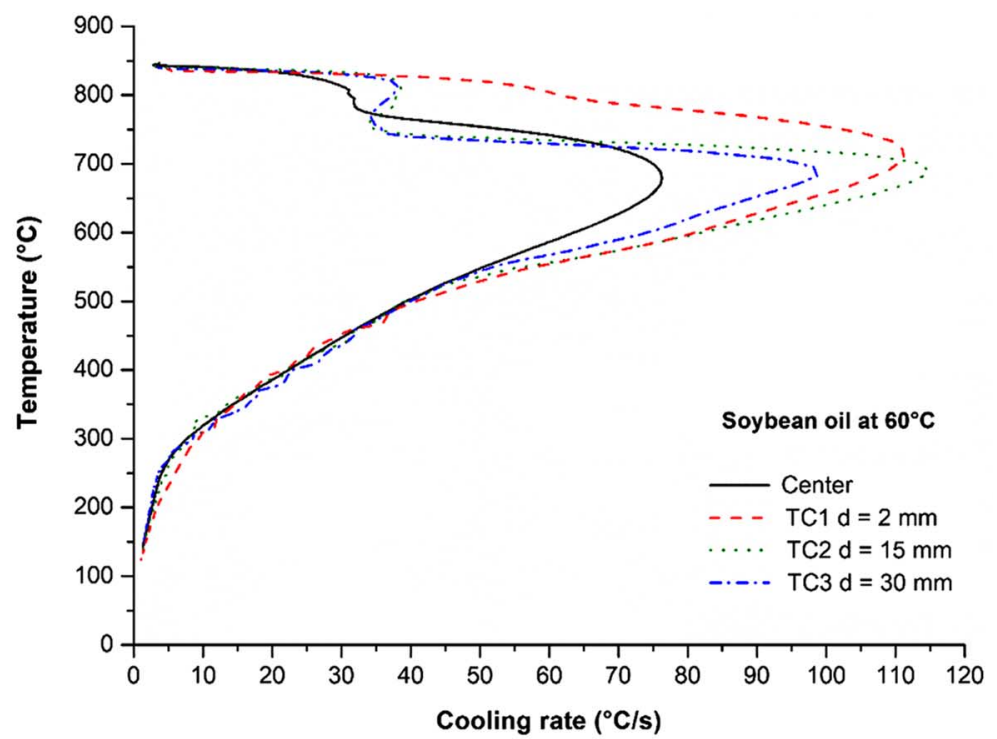

(b)

Of the vegetable oils evaluated, palm oil exhibited the longest time for transition from nucleate boiling to film boiling $\left(t_{\mathrm{A}-\mathrm{B}}\right)$, with coconut oil slightly less. This transition time represents the length of time for the duration of the apparent film-boiling behavior observed. Cottonseed oil exhibited the shortest transition time. The remaining vegetable oils exhibited relatively comparable transition times more similar to cottonseed oil than coconut or palm oils.

The temperature wherein the apparent transition from film boiling to nucleate boiling occurred $\left(T_{\mathrm{A}-\mathrm{B}}\right)$ was lowest for both palm and coconut oils and highest for cottonseed oil. The $T_{\mathrm{A}-\mathrm{B}}$ transition temperatures for the remaining vegetable oils were 


\section{FIG. 11}

(a) Cooling time-temperature curve for sunflower oil at $60^{\circ} \mathrm{C}$, no agitation (using Tensi probe). (b) Cooling rate curve for sunflower oil at $60^{\circ} \mathrm{C}$, no agitation (using Tensi probe).

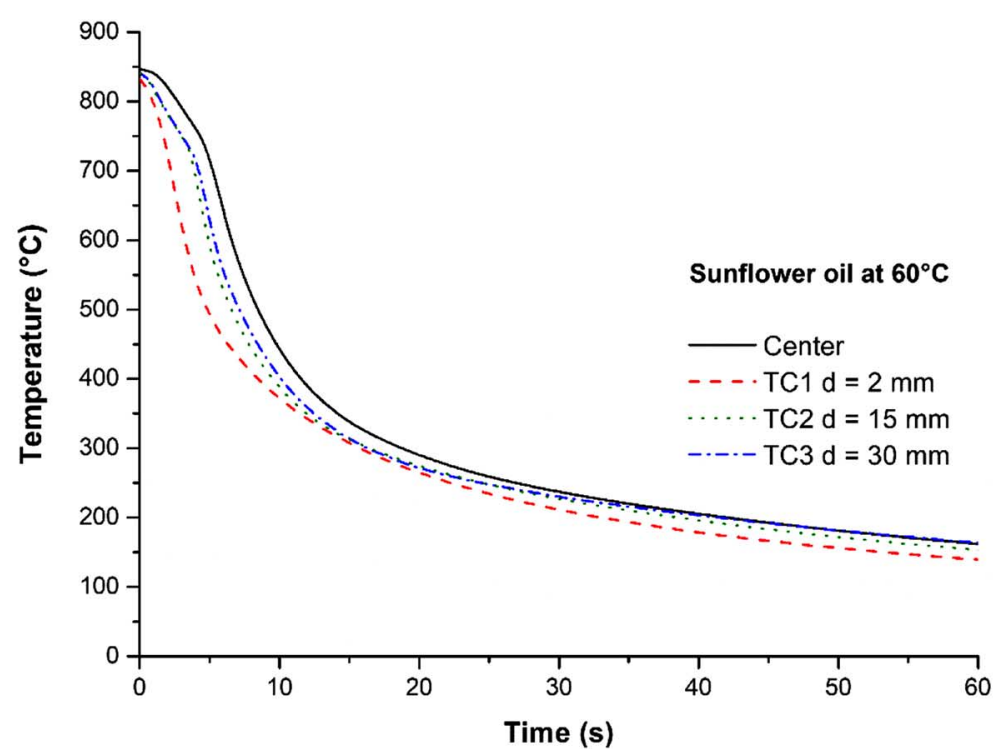

(a)

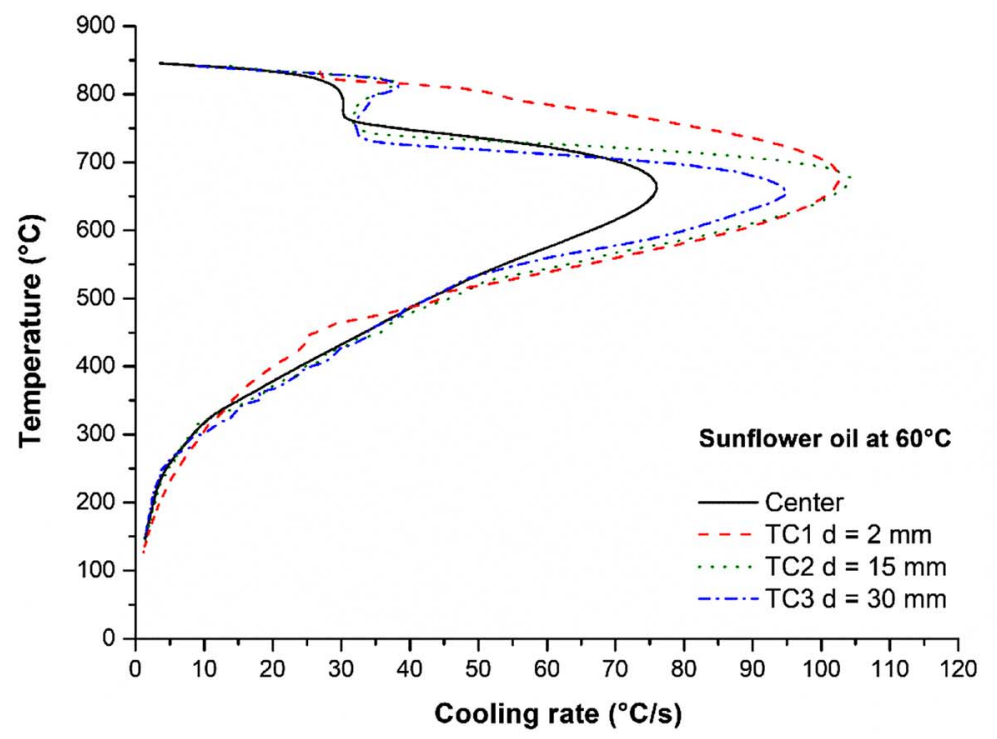

(b)

intermediate between these two limits but closer to the transition temperatures exhibited by cottonseed oil.

Perhaps two of the most critical parameters are the maximum cooling rate $\left(C R_{\max }\right)$ and the temperature at which this occurs $\left(T_{C R \max }\right)$. For the vegetable oils evaluated, coconut oil exhibited the lowest maximum cooling rate, and the highest maximum cooling rates were observed for canola, soybean, and sunflower oils. The remaining $C R_{\max }$ values were similar, although slightly lower than the highest values. For the temperature at which the maximum cooling rate occurred, coconut and palm oil exhibited the lowest $T_{C R \max }$ 


\section{FIG. 12}

(a) Cooling time-temperature curve for Houghto-Quench HKM petroleum oil (fast quench oil) at $60^{\circ} \mathrm{C}$, no agitation (using Tensi probe). (b) Cooling rate curve for Houghto-Quench HKM petroleum oil (fast quench oil) at $60^{\circ} \mathrm{C}$, no agitation (using Tensi probe).

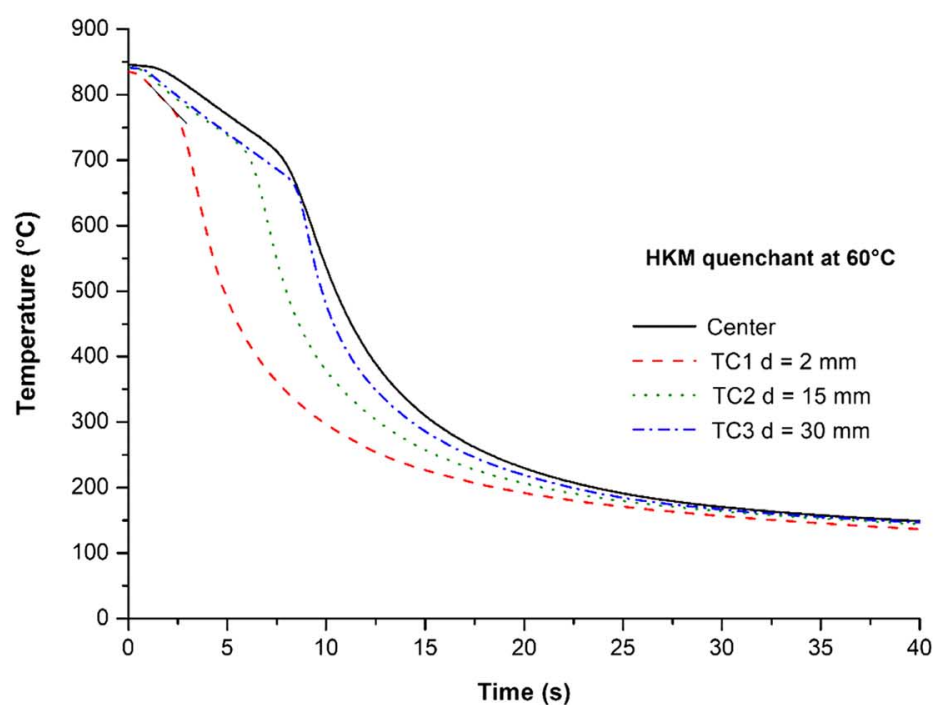

(a)

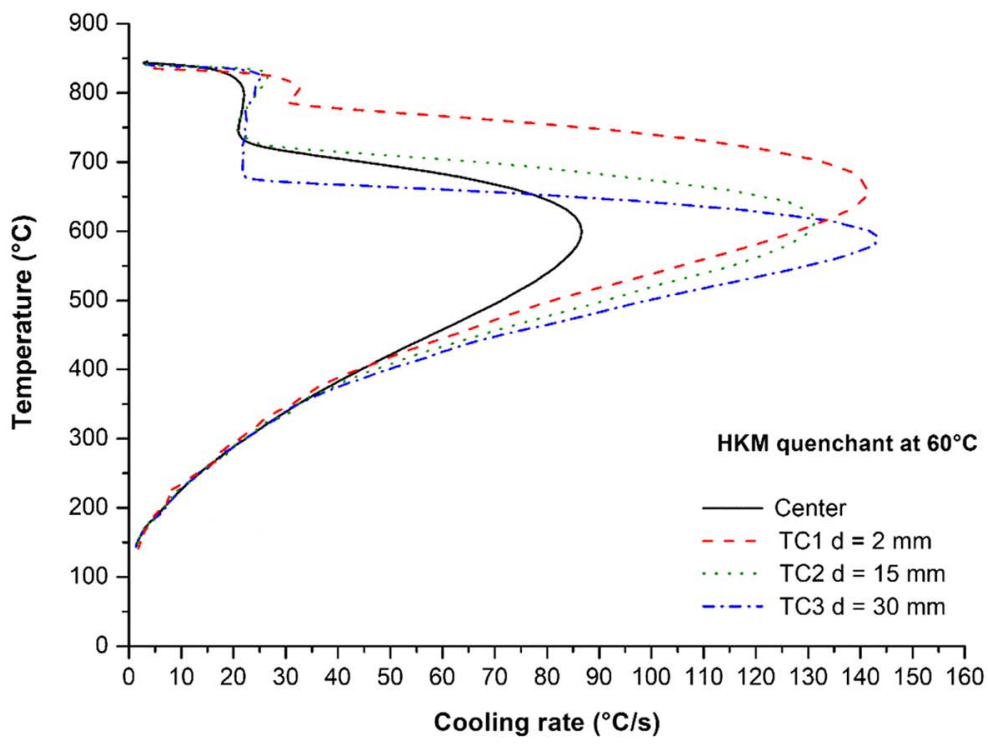

(b)

temperatures and peanut oil exhibited the highest temperature. The $T_{C R \max }$ values for the remaining oils were intermediate between these limits.

The cooling rates at $300^{\circ} \mathrm{C}\left(C R_{300}\right)$ and $200^{\circ} \mathrm{C}\left(C R_{200}\right)$ were determined and are shown in Table 3. Of these, the value most often cited is the $C R_{300}$ value. The highest $C R_{300}$ was obtained with canola oil, followed by corn and sunflower oils. The remaining vegetable oils exhibited intermediate values.

The times to cool to $300^{\circ} \mathrm{C}\left(t_{300}\right)$ and $200^{\circ} \mathrm{C}\left(t_{200}\right)$ were determined. Of the vegetable oils shown in Table 3, coconut, cottonseed, and peanut oils exhibited the longest $t_{300}$ time. Canola, corn, soybean, and sunflower oils exhibited the shortest $t_{300}$ time. Palm oil 


\section{FIG. 13}

(a) Cooling time-temperature curve for Houghto-Quench H10O petroleum oil

(conventional-slow quench oil) at $60^{\circ} \mathrm{C}$, no agitation (using Tensi probe). (b) Cooling rate curve for Houghto-Quench H10O petroleum oil (conventional quench oil) at $60^{\circ} \mathrm{C}$, no agitation (using Tensi probe).

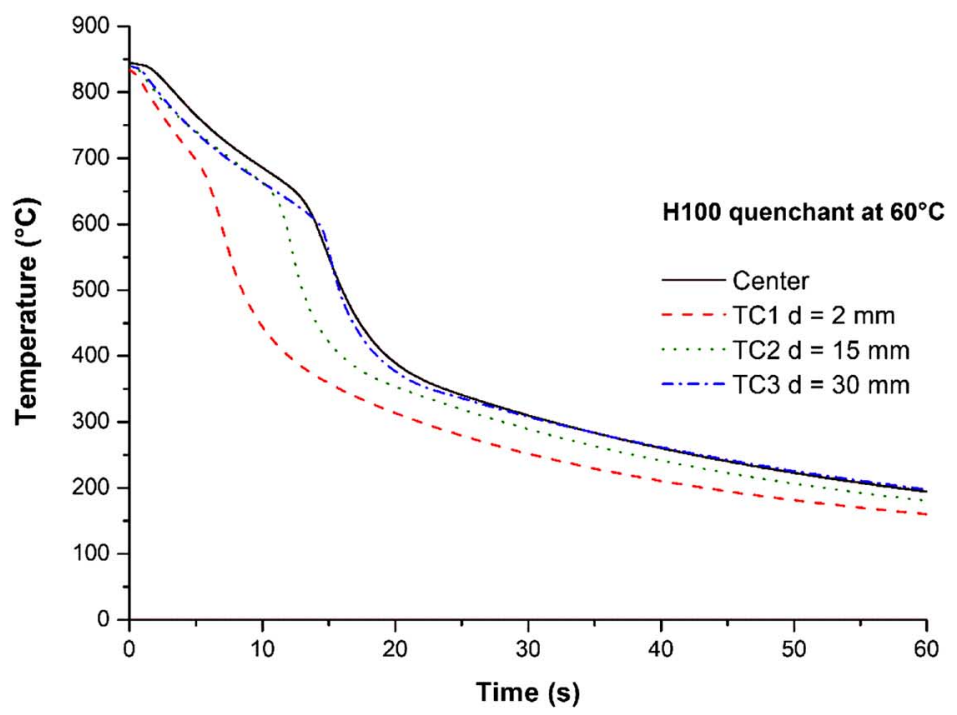

(a)

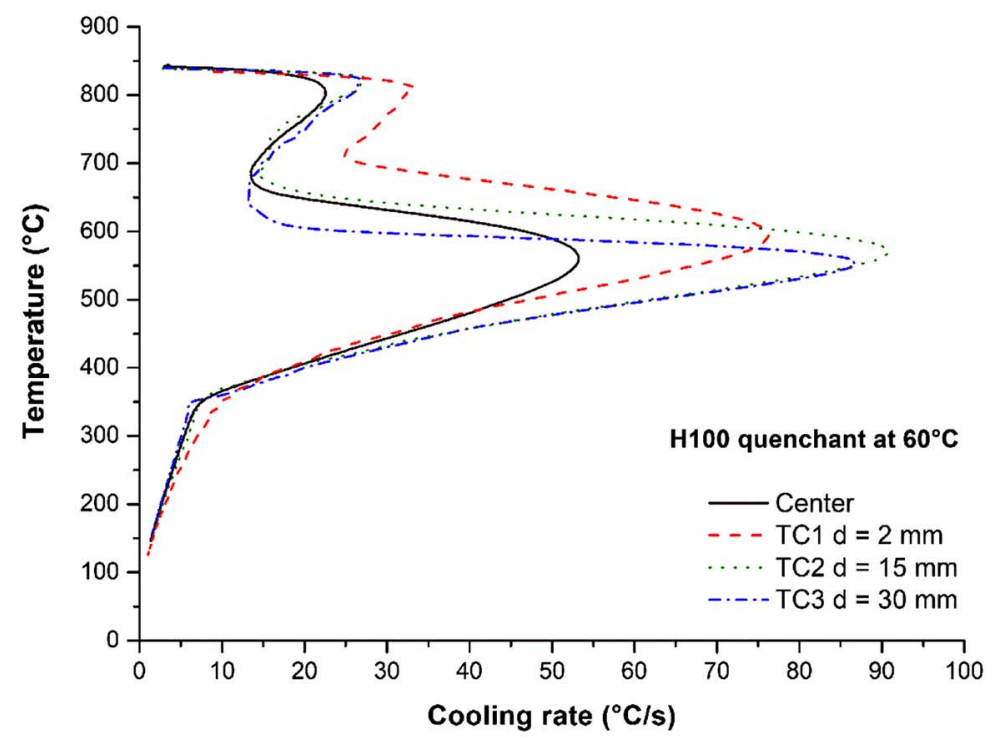

(b)

exhibited an intermediate cooling time. At $200^{\circ} \mathrm{C}$, the shortest $t_{200}$ value was obtained with canola oil (cools the fastest of the oils evaluated to $200^{\circ} \mathrm{C}$ ) and the longest $t_{200}$ times were obtained with coconut, cottonseed, and peanut oils. The remaining vegetable oils exhibited intermediate cooling times to $200^{\circ} \mathrm{C}$.

The various cooling parameters for the vegetable oils do differ from each other, but these differences must be understood relative to the quenching performance exhibited by a range of petroleum oil-based quenchants. For this evaluation, the "fast" petroleum quenching oil is represented by Houghto-Quench HKM, and the "slow" conventional quench oil is represented by Houghto-Quench H100. The Tensi probe centerline cooling 
TABLE 2

Figure numbers and identities of cooling time-temperatures and cooling rate curves obtained with Tensi Probe (see Fig. 1) at $60^{\circ} \mathrm{C}$, no agitation.

Figure Number

\begin{tabular}{lcc}
\cline { 2 - 3 } Quenchant & Cooling-Time Temperature Curve & Cooling Rate Curve \\
\hline Vegetable Oils & $4 \mathrm{a}$ & \\
Canola Oil & $5 \mathrm{a}$ & $4 \mathrm{~b}$ \\
Coconut Oil & $6 \mathrm{a}$ & $5 \mathrm{~b}$ \\
Corn Oil & $7 \mathrm{a}$ & $6 \mathrm{~b}$ \\
Cottonseed Oil & $8 \mathrm{a}$ & $7 \mathrm{~b}$ \\
Palm Oil & $9 \mathrm{a}$ & $8 \mathrm{~b}$ \\
Peanut Oil & $10 \mathrm{a}$ & $9 \mathrm{~b}$ \\
Soybean Oil & $11 \mathrm{a}$ & $10 \mathrm{~b}$ \\
Sunflower Oil & & $11 \mathrm{~b}$ \\
Petroleum Oil Quenchants & $12 \mathrm{a}$ & \\
Houghto-Quench HKM & $13 \mathrm{a}$ & $12 \mathrm{~b}$ \\
Houghto-Quench H100 & & $13 \mathrm{~b}$ \\
\hline
\end{tabular}

curve parameters for these two quench oils are shown in Table 3. The fast oil exhibits a shorter time duration of film boiling $\left(t_{\mathrm{A}-\mathrm{B}}\right)$, which occurs at a higher temperature $\left(T_{\mathrm{A}-\mathrm{B}}\right)$ when compared to the slow oil. However, with respect to these two cooling parameters, all of the vegetable oils exhibited substantially shorter transition times $\left(t_{\mathrm{A}-\mathrm{B}}\right)$ and, with the exception of palm and coconut oils, occurred at higher transition temperatures $\left(T_{\mathrm{A}-\mathrm{B}}\right)$ than either petroleum oil quenchants.

The maximum cooling rate $\left(C R_{\max }\right)$ of the fast petroleum oil was substantially faster than any of the vegetable oils, and the $C R_{\max }$ for the conventional petroleum oil was much slower than any of the vegetable oils. The transition temperatures at which the maximum cooling rate occurs were lower for both petroleum oil quenchants relative to the vegetable oils. This would be expected since the film boiling duration was longer for the petroleum oils. Taken together, with respect to hardening, these data suggest that the cooling properties based on cooling times and rates of vegetable oils are intermediate, between fast and conventional petroleum oil quenchants.

TABLE 3

Cooling parameters obtained by ASTM D6200 at $60^{\circ} \mathrm{C}$ bath temperature and with no agitation.

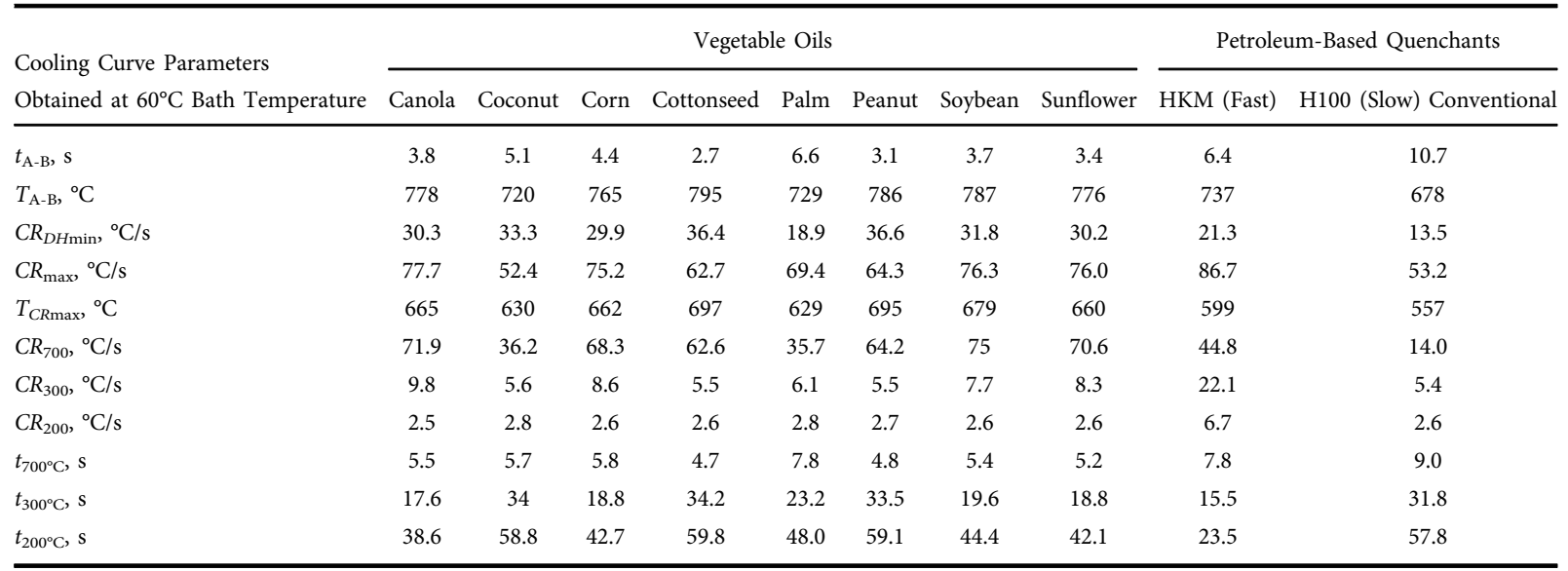


It is generally assumed that to optimize distortion control and minimize cracking potential, cooling rates at $300^{\circ} \mathrm{C}\left(C R_{\max }\right)$ should be minimized. The temperature of $300^{\circ} \mathrm{C}$ was selected since it approximates the martensite transition temperature for many carbon steels. For this work, both $C R_{300}$ and $C R_{200}$ and the times to cool to these temperatures $\left(t_{300}\right.$ and $\left.t_{200}\right)$ were also determined for the vegetable oils and petroleum oil quenchants in this study.

The fastest $C R_{300}$ and $C R_{200}$ values of all quenchants evaluated were exhibited by the fast petroleum quench oil, which is likely to be due to its significantly lower viscosity relative to the other oils evaluated (see Table 1). As expected, based on its viscosity, the $C R_{300}$ was substantially lower for the conventional (slow) petroleum oil quenchant. However, $C R_{300}$ cooling rates for some vegetable oils, coconut, cottonseed, and peanut oils, were essentially equivalent to the conventional. The $C R_{300}$ value for palm oil was similar but slightly faster than the slowest vegetable. While the $C R_{300}$ values for the remaining vegetable oils, canola, corn, soybean, and sunflower oils, were somewhat faster than the slowest examples, all oils were considerably slower than the fast petroleum oil. The $C R_{200}$ values were all comparably slow, and all were substantially slower than the fast petroleum quenching oil.

The fastest cooling times to $300^{\circ} \mathrm{C}\left(t_{300}\right)$ were obtained by the fast petroleum quenching oil, with canola, corn, soybean, and sunflower oils exhibiting times only slightly slower. The slowest $t_{300}$ values were obtained with coconut, cottonseed, and peanut oils, which were comparable to the $t_{300}$ cooling time exhibited by the conventional quenching oil. The remaining vegetable oils exhibited intermediate $t_{300}$ values. Similar results were obtained to the cooling times to $200^{\circ} \mathrm{C}\left(t_{200}\right)$.

With respect to the ability of vegetable oil quenchants to provide distortion control potential and cracking minimization, the cooling curve data obtained suggest that coconut, cottonseed, and peanut oils would provide the best results, although all vegetable oils evaluated would provide results superior to the fast petroleum quenching oil.

\section{SURFACE HEAT FLUX COMPARISONS}

The surface heat flux values obtained when quenching the Tensi multiple-thermocouple probe (see Fig. 1) in the vegetable oils of this study, relative to a fast petroleum quenching oil and a conventional petroleum quenching oil, were compared, and the results are shown in Fig. 14a and b and summarized in Table 4. The computational methodology used to obtain surface heat flux values was described in detail previously in this report.

Of the vegetable oils, the lowest heat flux values, $Q_{\max }$, were obtained with coconut and peanut oils, and these values were equivalent to the $Q_{\max }$ value obtained with the conventional petroleum oil quenchant. All of the quenchants, both vegetable oils and the conventional petroleum quench oil, exhibited a $Q_{\max }$ value lower than that exhibited by the fast petroleum quenching oil. Of the vegetable oils, canola and soybean oils exhibited the highest $Q_{\max }$ value, although still lower than the fast petroleum quenching oil. The remaining vegetable oils, corn, cottonseed, palm, and sunflower oils, exhibited approximately comparable values intermediate between the two petroleum quench oils shown in Table 4.

With the exception of palm oil (because of the prolonged film-boiling behavior), all of the vegetable oils exhibited transition temperatures at which $Q_{\max }$ occurs $\left(T_{\max }\right)$. The cooling times to achieve $Q_{\max }\left(t_{\max }\right)$ were much longer for the conventional petroleum oil quenchant than the fast petroleum oil quenchant and any of the vegetable oils. All of the vegetable oils exhibited shorter $t_{\max }$ values than the fast petroleum oil, although 
FIG. 14 (a) Surface heat flux as a function of time for the vegetable oils in this study: canola, coconut, corn, cottonseed, palm, and peanut oils. These data were calculated from the centerline thermocouple time-temperature data obtained $60^{\circ} \mathrm{C}$ under unagitated conditions, using the Tensi probe shown in Fig. 1. (b) Surface heat flux as a function of time for the vegetable oils in this study: soybean and sunflower oils and the fast and conventional petroleum oils used for comparison in this work. These data were calculated from the centerline thermocouple time-temperature data obtained $60^{\circ} \mathrm{C}$ under unagitated conditions, using the Tensi probe shown in Fig. 1.
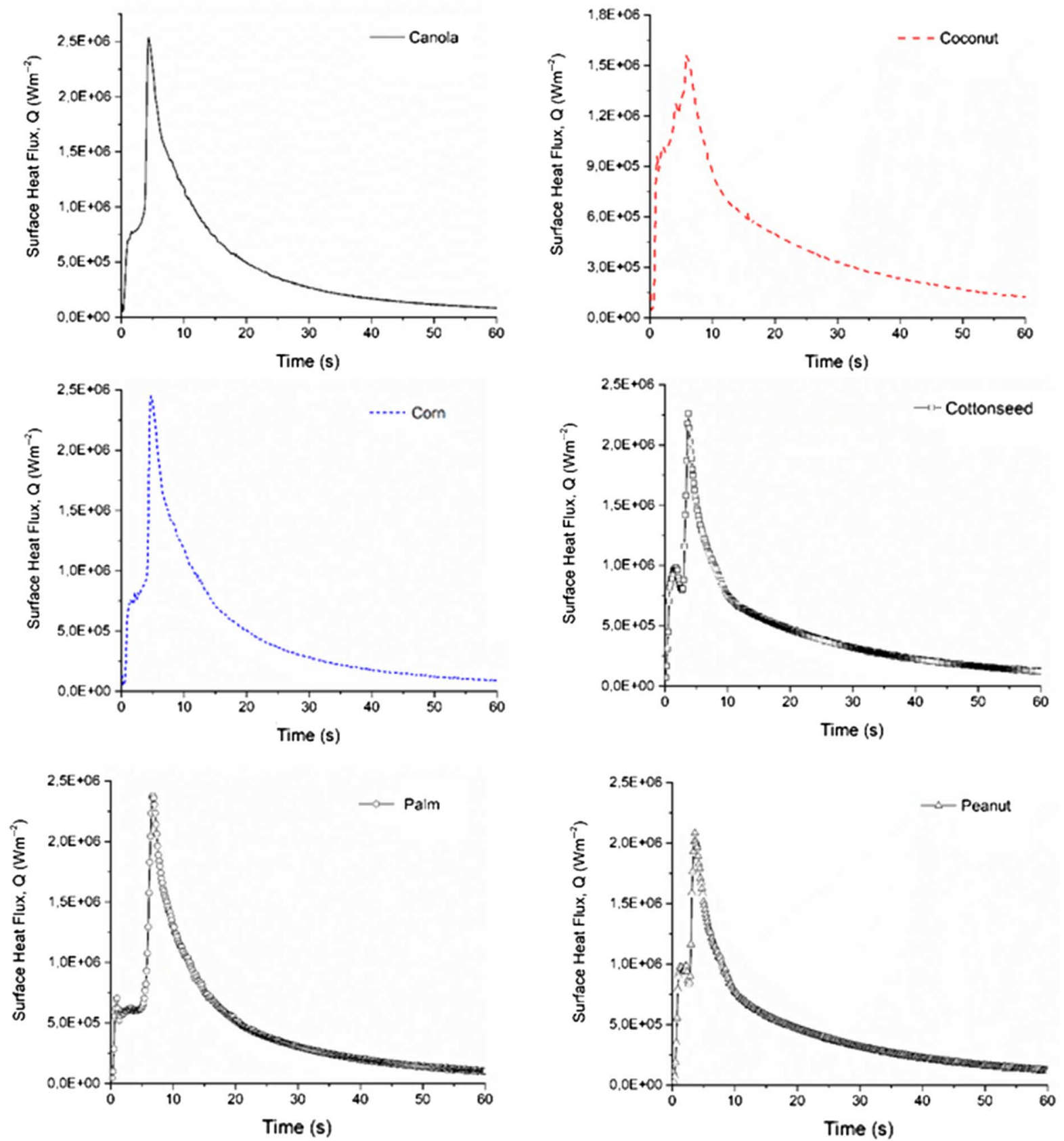

(a) 
FIG. 14 Continued
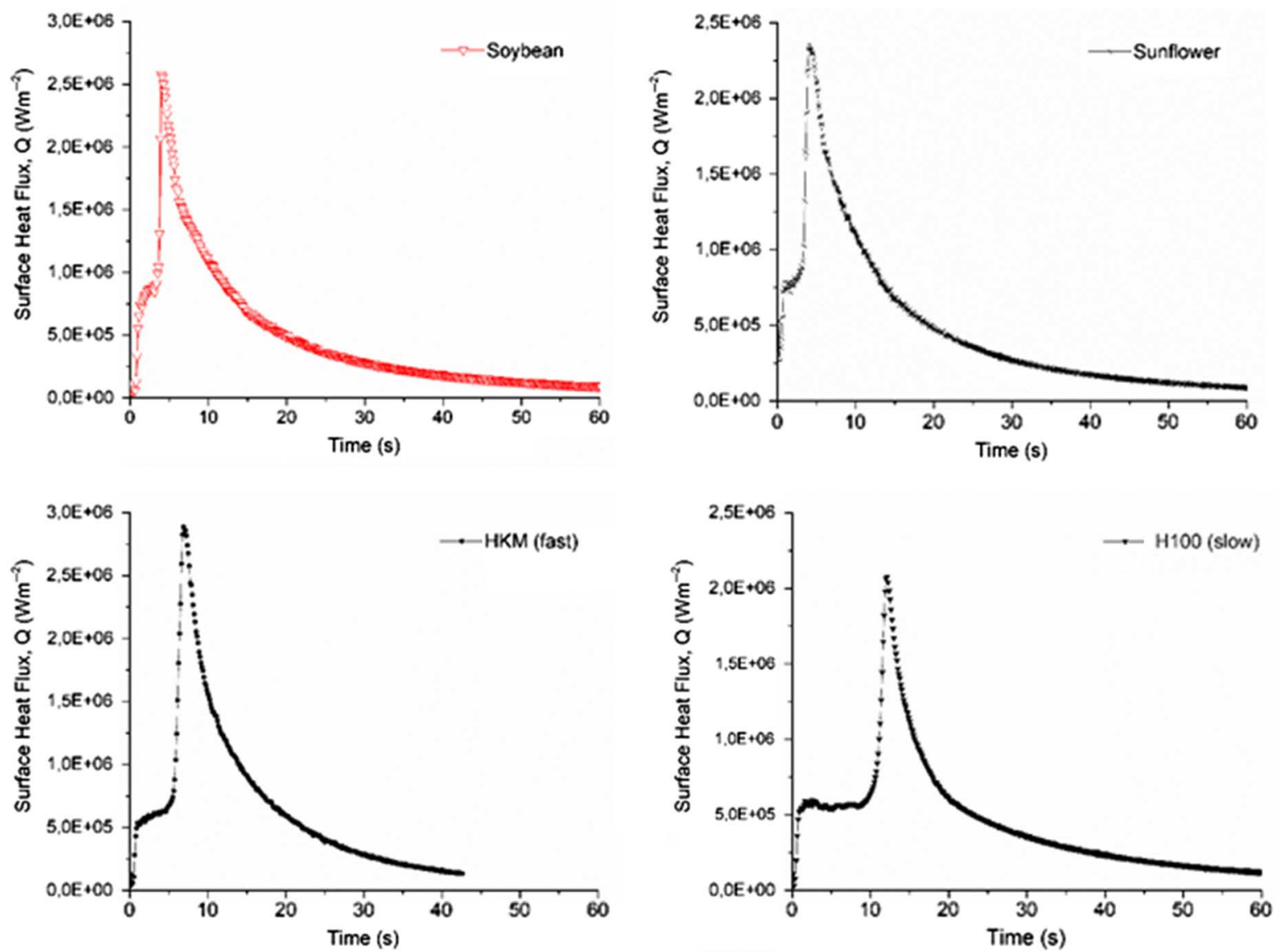

(b)

TABLE 4

Surface heat flux determined for all vegetable oils and petroleum oil based quenchants.

\begin{tabular}{lccc}
\hline & \multicolumn{3}{c}{ Surface Heat Flux } \\
\cline { 2 - 4 } Vegetable Oils & $t_{\max }, \mathrm{s}$ & $T_{\max },{ }^{\circ} \mathrm{C}$ & $\mathrm{Q}_{\max } \times 10^{6}, \mathrm{Wm}^{-2}$ \\
\hline Canola & 4.375 & 535.61 & 2.54 \\
Coconut & 5.750 & 510.35 & 1.56 \\
Corn & 4.750 & 531.65 & 2.45 \\
Cottonseed & 3.750 & 554.06 & 2.26 \\
Palm & 6.750 & 486.25 & 2.38 \\
Peanut & 3.625 & 562.43 & 2.08 \\
Soybean & 4.000 & 583.24 & 2.58 \\
Sunflower & 4.125 & 532.88 & 2.35 \\
Petroleum-Based Oils & & & 2.89 \\
HKM (Fast) & 6.875 & 441.44 & 2.08 \\
H100 (Slow)(Conventional) & 12.125 & 422.75 & \\
\hline
\end{tabular}


the $t_{\max }$ value for palm oil (followed by coconut oil) was approximately comparable. The shortest $t_{\max }$ values were obtained for cottonseed and peanut oils.

Based on the $Q_{\max }$ characterization, of the vegetable oils, coconut and peanut oils appear to perform most like a conventional petroleum oil, and canola and soybean oils seem to be more comparable to a fast petroleum oil quenchant. The other vegetable oils evaluated exhibited intermediate maximum heat flux.

\section{Conclusions}

The viscosity, rewetting, cooling curve performance, and heat transfer properties of a number of vegetable oils commonly available in supermarkets in North and South America were comparatively evaluated. These natural, renewable oils included canola, coconut, corn, cottonseed, palm, peanut, soybean, and sunflower oils, and they were used in their as-purchased condition, without subsequent additional purification. The properties obtained were compared to two commercially available petroleum oil-based quenchants: a "fast" (accelerated) oil, Houghto-Quench HKM, and a conventional (slow) oil, Houghto-Quench H100.

A comparison of the viscosity properties showed that all of the vegetable oils exhibited kinematic viscosities at $40^{\circ} \mathrm{C}$ in the range of approximately 28-39 cSt, with coconut oil (27.9 cSt) exhibiting the lowest and peanut oil $(38.6 \mathrm{cSt})$ exhibiting the highest viscosities. These viscosities were greater than those exhibited by the petroleum oil quenchants, in which the fast oil was $13.7 \mathrm{cSt}$ and the conventional petroleum oil was $19.5 \mathrm{cSt}$. All of the viscosities obtained were similar to values reported in the literature. The VI index for all the vegetable oils was much greater than the values obtained for the petroleum oils, indicating that the vegetable oils possessed significantly less viscosity temperature variation than either the fast or conventional petroleum oil quenchants.

The cooling curve behavior of each vegetable oil and petroleum oil candidate was obtained at $60^{\circ} \mathrm{C}$ without agitation, as per ASTM D6200, using the Tensi multiple (4)-thermocouple Inconel 600 probe illustrated in Fig. 1. With the exception of palm oil, all of the vegetable oils exhibited minimal evidence of film boiling. The rewetting properties suggested excellent quench uniformity with predominantly convective heat transfer. Since vegetable oils do not boil, any film-boiling properties observed, such as for palm oil, suggests the presence of significant quantities of volatile by-products not adequately removed by the refining process or potential subsequent degradation. This was not studied further in this work. Interestingly, in this study, peanut oil did not exhibit the presence of film boiling. Both petroleum quenchants did exhibit wetting front movement from the bottom of the Tensi probe to the upper surface thermocouple position not observed with any of the vegetable oils.

An extensive analysis of the cooling curves obtained using the thermocouple placed at the geometric center of the Tensi probe provided data that may be summarized as follows:

(1) For the vegetable oils evaluated, coconut oil exhibited the lowest maximum cooling rate, and the highest maximum cooling rates were observed for canola, soybean, and sunflower oils.

(2) For the temperature at which the maximum cooling rate occurred, coconut and palm oil exhibited the lowest $T_{C R \max }$ temperatures, and peanut oil exhibited the highest temperature. The $T_{C R \max }$ values for the remaining oils were intermediate between these limits. 
(3) Of the cooling rates at lower temperatures, the cooling rate at $300^{\circ} \mathrm{C}\left(C R_{300}\right)$ value is often the most commonly reported. The highest $C R_{300}$ was obtained with canola oil, followed by corn and sunflower oils. The remaining vegetable oils exhibited intermediate values.

(4) The Tensi probe centerline cooling curve parameters for the fast and conventional petroleum quench oils was obtained, and the cooling curve data showed that, as expected, the fast oil exhibited a faster maximum cooling rate $\left(C R_{\max }\right)$ and shorter time duration of film boiling $\left(t_{\mathrm{A}-\mathrm{B}}\right)$, which occurred at a higher temperature $\left(T_{\mathrm{A}-\mathrm{B}}\right)$ when compared to the slow oil. The $C R_{300}$ was also faster for the fast oil than the conventional petroleum quench oil. Typically, the vegetable oil cooling curve behavior was intermediate between the data obtained for either petroleum oil quenchant.

(5) With respect to the ability of vegetable oil quenchants to provide distortion control potential and cracking minimization, the cooling curve data obtained suggest that coconut, cottonseed, and peanut oils would provide the best results, although all vegetable oils evaluated would provide results superior to the fast petroleum quenching oil.

Finally, the maximum heat flux $\left(Q_{\max }\right)$ values were determined for the vegetable oils and petroleum oil quenchants studied. The data showed that this is an excellent discriminatory and meaningful characterization method. The data obtained in this study showed that the fast petroleum oil exhibited a significantly greater $Q_{\max }$ than any of the other oils, vegetable oils or the conventional petroleum oil. Canola oil showed the lowest $Q_{\max }$, and peanut oil and conventional petroleum oil exhibited equivalent $Q_{\max }$ values. The other vegetable oils exhibited $Q_{\max }$ values intermediate between the fast and conventional petroleum quenchants.

\section{ACKNOWLEDGMENTS}

The authors acknowledge their appreciation to CAPES (Coordenação de Aperfeiçoamento de Pessoal de Nível Superior) and University of São Paulo (USP) for the financial support of this work.

The authors express sincere appreciation to Dr. Scott MacKenzie of Houghton International for his assistance in obtaining thermophysical property data for the petroleum oil quenchants reported here. Also, special appreciation to Houghton Brazil Ltda. for providing the petroleum oil quenchants used for this work.

\section{References}

[1] Simencio-Otero, R. L., Canale, L. C., and Totten, G. E., "Use of Vegetable Oils and Animal Oils as Steel Quenchants: A Historical Review-1850-2010," J. ASTM Int., Vol. 9, No. 1, 2012, pp. 1-38, https://doi.org/10.1520/JAI103534

[2] Simencio Otero, R. L., Canale, L. C., Totten, G. E., and Meekisho, L., "Vegetable Oils as Metal Quenchants: A Comprehensive Review," Mater. Perform. Charact., Vol. 6, No. 1, 2017, pp. 174-250, https://doi.org/10.1520/MPC20160112

[3] United States Environmental Protection Agency, "Environmentally Acceptable Lubricants," Report EPA 800-R-11-002, United States Environmental Protection Agency, Office of Wastewater Management, Washington, DC, 2011, 27p.

[4] Anon, "Penn State "Green" Hydraulic Fluids - A Fact Sheet," Technical Information Bulletin, Penn State University, College Station, PA, 2006.

[5] El Kinawy, O., El-Hamidi, M., and Abdallah, R., "Utilization of Non Edible Oils in Lubrication as Substitution to Mineral Oils," J. Appl. Sci. Res., Vol. 9, No. 6, 2013, pp. 3492-3496. 
[6] Erhan, S. Z., Sharma, B. K., and Perez, J. M., "Oxidation and Low Temperature Stability of Vegetable Oil-Based Lubricants," Ind. Crops Prod., Vol. 24, No. 3, 2006, pp. 292-299, https://doi.org/10.1016/j.indcrop.2006.06.008

[7] Weller, D. E., Jr. and Perez, J. M., "A Study of the Effect of Chemical Structure on Friction and Wear: Part 2-Vegetable Oils and Esters," Lubr. Eng., Vol. 57, No. 5, 2001, pp. 20-26.

[8] Tagaya, M. and Tamura, I., "Studies on the Quenching Media: Third Report, the Cooling Ability of Oils," Technology Report No. 123, Osaka University, Osaka, Japan, Vol. 4, 1954, pp. 305-319.

[9] Tagaya, M. and Tamura, I., "On the Deterioration of Quenching Oils," Technology Report No. 274, Osaka University, Osaka, Japan, Vol. 7, 1957, pp. 403-424.

[10] de Souza, E. C., Fernandes, M. R., Augustinho, S. C., de Campos Fraceschini Canale, L., and Totten, G. E., "Comparison of Structure and Quenching Performance of Vegetable Oils," J. ASTM Int., Vol. 6, No. 9, 2009, pp. 1-25, https://doi.org/10.1520/ JAI102188

[11] Carvalho de Souza, E., Canale, L. C. F., Sarmiento, G. S., Agaliotis, E., Carrara, J. C., Schicchi, D. S., and Totten, G. E., "Heat Transfer Properties of a Series of Oxidized and Unoxidized Vegetable Oils in Comparison with Petroleum Oil-Based Quenchants," J. Mater. Eng. Perform., Vol. 22, No. 7, 2013, pp. 1871-1878, https://doi.org/10.1007/s11665-013-0514-2

[12] Jagannath, V. and Prabhu, K. N., "Severity of Quenching and Kinetics of Wetting of Nanofluids and Vegetable Oils," J. ASTM Int., Vol. 6, No. 3, 2009, pp. 1-9, https://doi. org/10.1520/JAI101800

[13] Ramesh, G. and Narayan Prabhu, K. N., "Wetting and Cooling Performance of Vegetable Oils during Quench Hardening," Heat Transfer Asian Res., Vol. 45, No. 4, 2016, pp. 342-357, https://doi.org/10.1002/htj.21165

[14] Agboola, J. B., Kamardeen, O. A., Mudiare, E., Adeyemi, M. B., and Afolabi, S. A., "Performance Assessment of Selected Nigerian Vegetable Oils as Quenching Media in Hardening Process for Medium Carbon Steel," J. Min. Mater. Char. Eng., Vol. 3, No. 2, 2015, pp. 85-93, https://doi.org/10.4236/jmmce.2015.32011

[15] Otero, R. L. S., "Calculation of Kobasko's Simplified Heat Transfer Coefficients from Cooling Curve Data Obtained with Small Probes," J. ASTM Int., Vol. 9, No. 4, 2012, pp. 1-8, https://doi.org/10.1520/JAI104304

[16] Kobasko, N. I., Batista, A. A., Canale, L. C., Totten, G. E., and Dobryvechir, V. V., "Cooling Capacity of Coconut Oil, Palm Oil, and a Commercial Petroleum Oil by Solving the Heat Conductivity Inverse Problem," Mater. Perform. Charact., Vol. 2, No. 1, 2013, pp. 319-338, https://doi.org/10.1520/MPC20120047

[17] Liščić, B., "Measurement and Recording of Quenching Intensity in Workshop Conditions Based on Temperature Gradients," Mater. Perform. Charact., Vol. 5, No. 1, 2016, pp. 209-226, https://doi.org/10.1520/MPC20160007

[18] Matijevic, B., Liscic, B., Totten, G. E., and Canale, L. C. F., "Comparative Measurement and Evaluation of the Quenching Intensity of Palm Oil, Canola Oil and a Conventional Petroleum Oil Quenchant Based on Temperature Gradient Measurements," Mater. Perform. Charact., Vol. 6, No. 5, 2017, pp. 757-776, https://doi.org/10.1520/MPC20170041

[19] Künzel, T., "Einfluss der Wiederbenetzung auf die allotrope Modifikationsänderung tauchgekühlter Metallkörper," Ph.D. thesis, Technical University of Munich, Munich, Germany, 1986.

[20] Totten, G. E. and Tensi, H. M., "Using Conductance Data to Characterize Quenchants," Heat Treat. Prog., Vol. 2, No. 5, 2002, pp. 1-4.

[21] Tensi, H. M., "Wetting Kinematics," Quenching Theory and Technology, 2nd ed., B. Liščić, H. M. Tensi, L. C. F. Canale, and G. E. Totten, Eds., CRC Press, Boca Raton, FL, 2010, pp. 179-204.

[22] ASTM D445-17a, Standard Test Method for Kinematic Viscosity of Transparent and Opaque Liquids (and Calculation of Dynamic Viscosity), ASTM International, West Conshohocken, PA, www.astm.org 
[23] ASTM D2270-10(2016), Standard Practice for Calculating Viscosity Index from Kinematic Viscosity at $40^{\circ} \mathrm{C}$ and $100^{\circ} \mathrm{C}$, ASTM International, West Conshohocken, PA, www.astm.org

[24] ASTM D6200-01(2017), Standard Test Method for Determination of Cooling Characteristics of Quench Oils by Cooling Curve Analysis, ASTM International, West Conshohocken, PA, www.astm.org

[25] Ingley, H. A., Vegetable Oils: Liquid Coolants for Solar Heating and Cooling Applications, Final Report, United States Department of Energy, Washington DC, 1980, 106p.

[26] Wolke, R. W., "Up in Smoke," Washington Post, 1999, http://web.archive.org/web/ 20181016043019/http://www.washingtonpost.com/wp-srv/WPcap/1999-12/15/070r121599-idx.html (accessed 16 Oct. 2018).

[27] Retlief, L., "Analysis of Vegetable Oils, Seeds and Beans by TGA and NMR Spectroscopy," Ph.D. thesis, University of Stellenbosch, Matieland, Stellenbosch, South Africa, 2011.

[28] Aluyor, E. O., Ozigagu, C. E., Oboh, O., and Aluyor, P., "Chromatographic Analysis of Vegetable Oils: A Review," Sci. Res. Essay, Vol. 4, No. 4, 2009, pp. 191-197.

[29] Gee, P. T., "Analytical Characteristics of Crude and Refined Palm Oil and Fractions," Eur. J. Lipid Sci. Technol., Vol. 109, No. 4, 2007, pp. 373-379, https://doi.org/10.1002/ ejlt.200600264

[30] Lang, W., Sokhansanj, S., and Sosulski, F. W., "Modelling the Temperature Dependence of Kinematic Viscosity of Refined Canola Oil," J. Am. Oil Chem. Soc., Vol. 69, No. 10, 1992, pp. 1054-1055, https://doi.org/10.1007/BF02541080

[31] Fasina, O. O. and Colley, Z., "Viscosity and Specific Heat of Vegetable Oils as a Function of Temperature: $35^{\circ} \mathrm{C}$ to $180^{\circ} \mathrm{C}$," Int. J. Food Prop., Vol. 11, No. 4, 2008, pp. 738-746, https://doi.org/10.1080/10942910701586273

[32] Tangsathitkulchai, C., Sittichaitaweekul, Y., and Tangsathitkulchai, M., "Temperature Effect on the Viscosities of Palm Oil and Coconut Oil Blended with Diesel Oil," J. Am. Oil Chem. Soc., Vol. 81, No. 4, 2004, pp. 401-405, https://doi.org/10.1007/s11746004-0913-8

[33] Eryilmaz, T., Yesilyurt, M. K., Yumak, H., Arslan, M., and Sahin, S., "Determination of the Fuel Properties of Cottonseed Oil Methyl Ester and Its Blends with Diesel Fuel," Int. J. Automot. Eng. Technol., Vol. 3, No. 2, 2014, pp. 79-90, https://doi.org/ 10.18245/ijaet.90992

[34] Ravindra, Y. and Guruswamy, T., "Evaluation of Physical Properties of Selected Vegetable Oils and Their Blends with Diesel," Karnataka J. Agric. Sci., Vol. 14, No. 2, 2001, pp. 528-531. 